Mens

revue d'histoire intellectuelle de l'Amérique française

MENS

\title{
De la rue de Rome au Canada français : influences ou transferts?
}

\section{Olivier Dard}

Volume 8, numéro 1, automne 2007

URI : https://id.erudit.org/iderudit/1023147ar

DOI : https://doi.org/10.7202/1023147ar

Aller au sommaire du numéro

Éditeur(s)

Centre de recherche en civilisation canadienne-française

ISSN

1492-8647 (imprimé)

1927-9299 (numérique)

Découvrir la revue

Citer cet article

Dard, O. (2007). De la rue de Rome au Canada français : influences ou transferts ? Mens, 8(1), 7-66. https://doi.org/10.7202/1023147ar
Résumé de l'article

Cette contribution s'emploie d'abord à définir ce qu'il faut entendre par maurrassisme en partant du cœur de son expression, la France. En second lieu, il s'agit, en remettant le Canada français en perspective (à travers une comparaison avec la Belgique), de s’interroger sur le degré de pénétration du maurrassisme comme sur sa nature en se demandant si l'on est en présence d'influences ou de transferts culturels et politiques. Enfin, nous montrerons que la vision du Canada français de Charles Maurras et de quelques maurrassiens français est bien davantage conditionnée par leur vision de la France que par un effort d'analyse sur le Canada français lui-même. 


\title{
DE LA RUE DE ROME AU CANADA FRANÇAIS : INFLUENCES OU TRANSFERTS ?
}

\author{
Olivier Dard \\ UFR sciences humaines et arts \\ Université Paul Verlaine - Metz
}

\section{Résumé}

Cette contribution s'emploie d'abord à définir ce qu'il faut entendre par maurrassisme en partant du cœur de son expression, la France. En second lieu, il s'agit, en remettant le Canada français en perspective (à travers une comparaison avec la Belgique), de s'interroger sur le degré de pénétration du maurrassisme comme sur sa nature en se demandant si l'on est en présence d'influences ou de transferts culturels et politiques. Enfin, nous montrerons que la vision du Canada français de Charles Maurras et de quelques maurrassiens français est bien davantage conditionnée par leur vision de la France que par un effort d'analyse sur le Canada français lui-même.

\section{Abstract}

This essay seeks firstly to define maurrassism within the context of French political ideology. Secondly, it examines the degree to which maurrassism penetrated French Canada's intellectual culture. By comparing French Canada with Belgium, the author explores the extent to which one can speak of a genuine maurrassian influence in French Canada or rather of cultural and political transfers. Finally, the essay shows that the vision of French Canada beld by Charles Maurras and bis disciples was primarily conditioned by their vision of France and was not, therefore, the result of a real effort to understand French Canada itself. 
Bien au-delà d'une dispute universitaire, la question du maurrassisme au Canada français est largement débattue. En effet, elle met en jeu la question du conservatisme et de la tradition $^{1}$. Elle concerne également une figure centrale de l'histoire du Canada français au XX $\mathrm{XX}^{\mathrm{e}}$ siècle, l'abbé Lionel Groulx et son orientation idéologique dont il faut relever la "luxuriance des études» depuis quelques années ${ }^{2}$. Les sousentendus politiques de cette querelle sont perceptibles : le maurrassisme (rarement défini voire assimilé sans grand sens au fascisme) est brandi pour être amalgamé à la « grande noirceur » dont Lionel Groulx, épigone supposé de Maurras, serait le maître à penser.

La controverse historiographique est ancienne. Dès 1956, Michael Oliver avait soutenu la thèse d'un ancrage maurrassien du groulxisme ${ }^{3}$. Cette vision s'est développée, enrichie au cours des décennies suivantes. Elle est reprise par Yvan Lamonde selon qui «l'homonymie n'est pas que celle du titre des périodiques publiés de part et d'autre de l'Atlantique ; elle est plus globale et c'est celle de traditions intellectuelles partageables et partagées par ceux qui, au Canada français lisent L'Action française de Paris, Barrès, Maurras, 'Daudet, Bainville et par ceux qui entretiennent des liens personnels avec les gens de la rue de Rome ${ }^{4}$. Cette vision d'une Action française (AF) exportée au Canada français est relayée dans l'historiographie française par les travaux de Catherine Pomeyrols pour qui l'empreinte du maurrassisme au Canada français serait profonde 5 . D'autres études, conduites en particulier de façon très minutieuse par Pierre Trépanier, sans nier cette imprégnation, la relativisent considérablement et refusent de voir le Québec assimilé de fait, par le biais de cette greffe, à « une province culturelle de la France ${ }^{6}$ ».

La présente contribution, nourrie des travaux canadiens et français mais également fondée sur le dépouillement de 
revues (Vivre, La Nation) et de sources d'archives (la correspondance reçue par Charles Maurras du Canada français déposée au Centre d'accueil et de recherche des archives nationales (CARAN à Paris) s'emploiera à clarifier quelques questions restées trop souvent en suspens ${ }^{7}$. La première concerne ce qu'il faut entendre par maurrassisme et ce, en partant du cœur de son expression, à savoir la France. Ce point de départ est fondamental car il conditionne l'analyse qui peut être menée de ses réceptions hors de la France, et notamment au Canada français. Si le cadre de cette contribution est bilatéral, la relation franco-québécoise gagne beaucoup à être interrogée en prenant en compte d'autres foyers de réception du maurrassisme, à l'instar de la Belgique, catholique et francophone. Il sera loisible alors de s'interroger, non seulement sur le degré de pénétration du maurrassisme au Canada français, mais aussi sur la nature de cette dernière en se demandant si l'on est en présence d'influences ou de transferts culturels et politiques. Il s'agit d'essayer d'appliquer aux relations francocanadiennes une démarche et des concepts utilisés depuis les années 1980 dans le cadre d'études sur les relations culturelles franco-allemandes par des chercheurs comme Michel Espagne, Michael Werner ${ }^{8}$ ou Hans-Manfred Bock. Ce dernier n'hésite pas à qualifier une approche par « l'influence » de «catégorie naïve » et la rattache à une vision classique et selon lui datée des études des phénomènes de réception. Le fondement d'une telle démarche reposait sur «l'idée que des produits culturels, nés dans leur contexte culturel national, seraient sortis de ce milieu pour être transvasés dans la culture étrangère où ils auraient un effet véritable de catalyseurs?. " Hans-Manfred Bock lui oppose l'intérêt d'une approche par le «transfert» dont il résume ainsi les principaux traits : « Le transfert d'une production culturelle d'un pays à l'autre est inévitablement accompagné d'un processus de transforma- 
tion, car dans le pays d'accueil le produit importé est intégré dans un autre système de références et y gagne de nouvelles significations; ces importations culturelles correspondent le plus souvent chez les agents de la réception à des intérêts de légitimation ou de critique ${ }^{10}$. $\gg$ Il s'agira donc de s'interroger, à partir de l'existence du maurrassisme, moins sur son influence au Canada français que sur l'existence, ou non, d'un transfert culturel et politique. Enfin, nous analyserons le Canada de Charles Maurras et de quelques maurrassiens français pour montrer qu'il est bien davantage conditionné par leur vision de la France que par un effort d'analyse sur le Canada français lui-même.

\section{Jalons pour une définition du maurrassisme}

Né au tournant du $\mathrm{XX}^{\mathrm{e}}$ siècle, le maurrassisme, même s'il a beaucoup perdu de son influence, existe encore dans la France de 2007. Les héritiers de celui qu'ils appellent encore le «maitre de Martigues » ont joué un rôle non négligeable dans le combat souverainiste de droite contre le traité de Maastricht et la constitution européenne. Sur le plan de leurs relais, outre le mouvement la Restauration nationale et l'hebdomadaire Aspects de la France, ils disposent de différents organes récemment créés : Politique magazine, Les Épées et même la Nouvelle Revue universelle qui a commencé de reparaître en 2005.

Le maurrassisme s'inscrit donc dans une double dynamique de permanence et de mutations puisque si la filiation est revendiquée, elle s'est accompagnée de débats à l'intérieur de la nébuleuse maurrassienne, qu'il s'agisse de la Jeune droite durant l'entre-deux-guerres, de la Nation française du philosophe Pierre Boutang auquel collabora notamment l'historien Philippe Ariès du premier au dernier numéro (1955$\left.1966^{11}\right)$, ou du mensuel Jeune Révolution au lendemain de l'ef- 
fondrement de l'Organisation armée secrète $(\mathrm{OAS})^{12}$. Le maurrassisme peut être appréhendé à partir de trois éléments.

D'abord, sous l'angle doctrinal. Les ouvrages de Victor N'Guyen, de Michael Sutton et plus récemment de Bruno Goyet, de Stéphane Giocanti et de Domenico Fischella ont analysé les origines de la pensée maurrassienne qui se fixe au tournant du $\mathrm{XX}^{\mathrm{e}}$ siècle $^{13}$. D'inspiration réactionnaire et marquée par Auguste Comte, construite contre la philosophie des Lumières et le romantisme, elle signifie d'abord un refus radical de l'individualisme. Michael Sutton a justement relevé que "pour Maurras, le romantisme et les idées de 1789 n'étaient que deux aspects. du même mal, un individualisme qui exagère l'importance du sujet au détriment de l'ordre social et politique dont l'individu n'est qu'un élément transitoire ${ }^{14} »$. Maurras prône pour la France le rejet de la Troisième République au profit d'une monarchie décentralisatrice et s'emploie au début du $\mathrm{XX}^{e}$ siècle, dans le prolongement de l'affaire Dreyfus et sur fond de séparation de l'Église et de l'État, à rechercher une alliance avec les catholiques comme Auguste Comte l'avait en son temps entrepris à l'égard des Jésuites. Si la pensée maurrassienne nourrit l'Action française, l'homologie entre ces deux entités a ses limites. Maurras est une source essentielle mais non exclusive de l'Action française, qui, à travers son Institut, se pense comme une école. Dresser un état des lieux doctrinal de l'Action française impose la prise en compte d'autres publicistes de cette dernière. Ainsi, c'est Jacques Bainville qui forge sa doctrine en matière de politique extérieure et aussi en économie (en concurrence sur ce plan avec Georges Valois, présent à l'AF pendant vingt ans et qui s'est attaché, avant la rupture de 1925, à brosser les contours de «l'économie nouvelle »). Sur le plan religieux, fondamental au moins jusqu'en 1926 et la condamnation de l'AF par le Saint-Siège, outre Maurras, Henri Massis et, à un 
degré moindre, Jacques Maritain, jouent un rôle essentiel. Irriguée par une kyrielle de penseurs, l'Action française, ne présente pas sur l'ensemble des sujets une vision uniforme. Il en va de même en matière d'esthétique ou de littérature où les contrastes sont saisissants entre un Charles Maurras, gardien sourcilleux du classicisme, et Léon Daudet, qui peut s'en écarter et défendre vigoureusement dans les colonnes de L'Action frangaise et à l'académie Goncourt Voyage au bout de la nuit de Louis-Ferdinand Céline.

Une étude du maurrassisme impose d'examiner ses réceptions et donc de saisir, à travers l'étude de ses organisations, qui sont les maurrassiens (ligueurs, camelots, jeunes filles d'AF). Un triple problème se pose alors. Le premier concerne la mise en contexte et la chronologie : avant ou après la condamnation de 1926, après 1939 (levée des sanctions), après 1945 et le procès Maurras, etc. À chacun de ces moments, l'identité maurrassienne renvoie à des dimensions différentes. Ainsi, l'alliance avec les catholiques, essentielle avant 1926, ne l'est plus durant les années trente. En fait, la condamnation de 1926, si elle discrimine et suscite des départs (1260 entre la mi-décembre 1926 et la mi-novembre 1927), amène dans le même temps de nouvelles recrues à la Ligue (7910 adhérents pour la même période) $)^{15}$.

Il importe également de prendre en compte la sociologie des maurrassiens. À cet égard, les sources sont souvent lacunaires pour dresser une sociologie précise des droites nationales en France même si on dispose de monographies régionales. L'AF est implantée nationalement, quoique de façon inégale, et être maurrassien ne signifie pas la même chose à Paris ou en province. Ainsi, les travaux menés sur la Lorraine ont montré que la condamnation de 1926 a porté un coup sérieux à l'AF. L'alliance entre les monarchistes et des catholiques y était profonde et les militants, majoritairement 
catholiques pratiquants, ont suivi le pape ${ }^{16}$. En Bretagne, la condamnation de l'AF est un véritable " coup de tonnerre » et s'apparente à une "crise politique majeure » du fait des appuis de l'AF dans les élites sociales bretonnes ${ }^{17}$. Par ailleurs, les organes de presse maurrassiens en province livrent une vision atténuée des débats doctrinaux et des dissidences qui jalonnent cette histoire. Enfin, les différences sociologiques entre les militants sont à prendre en compte : si les Camelots $\mathrm{du}$ roi $^{18}$ sont la partie la plus active et donc la plus visible de l'AF, et ce tant à Paris qu'en province, ils ne sont pas toute l'AF.

Un troisième enjeu concerne l'influence de l'AF. Il s'agit d'en préciser les vecteurs et la portée, de poser la question des réseaux maurrassiens hors de l'Action française ès qualités et donc de souligner l'importance des périphéries maurrassiennes. Cette démarche est fondamentale pour apprécier la pesée globale du maurrassisme dans la France du $\mathrm{XX}^{\mathrm{e}}$ siècle mais elle comporte un danger et impose une limite : où s'arrêter? Pour s'en tenir aux intellectuels, Albert Thibaudet dans des articles ${ }^{19}$, Walter Benjamin dans sa correspondance à Gehrard Scholem ${ }^{20}$ ou Jules Romains dans le discours qu'il prononce à l'Académie française à l'occasion de la mort de Maurras ${ }^{21}$ reprennent à leur compte certaines analyses du penseur martégal ou lui rendent hommage. De tels documents permettent de souligner une influence du maurrassisme. Ils ne font pas pour autant de ces hommes des maurrassiens ni même des compagnons de route de l'AF. Encore une fois, la prise en compte du contexte est fondamentale. Le maurrassisme suscite adhésions (avec des degrés divers et des moments précis ${ }^{22}$ ) et rejets, parfois violents. Il est l'objet de débats alimentés par l'évolution générale du pays et les multiples affaires qui secouent la vie de l'AF, outre sa condamnation par le Saint-Siège : assassinat de Marius Plateau, 
mort de Philippe Daudet, agression contre Blum à l'occasion des funérailles de Jacques Bainville et interdiction de la Ligue, emprisonnement de Maurras, etc.

La question du rayonnement de l'AF déborde d'ailleurs la France et touche bien des pays ${ }^{23}$ en Europe, notamment en terres francophones $\left(\right.$ Belgique $^{24}$, Suisse ${ }^{25}$ ) mais aussi dans la péninsule ibérique, tant du côté portugais (Integralismo lusitan $0^{26}$ ) qu'espagnol ${ }^{27}$, sans oublier les Amériques, États-Unis compris $^{28}$. Durant les années trente, la relation ne fonctionne pas à sens unique. À cette époque, bien des jeunes maurrassiens français, déçus par la maison mère, observent avec le plus grand intérêt l'évolution de la situation à l'étranger, notamment en Belgique (Rex), en Roumanie (Garde de Fer) ou dans la péninsule ibérique ${ }^{29}$. Là encore, cette histoire doit être périodisée en fonction d'éléments propres à l'AF (cas de la condamnation et de ses incidences en Belgique, en rappelant le rôle du clergé belge dans la condamnation) ou propres aux histoires intellectuelles nationales. Ainsi de l'Espagne, où la pensée de Maurras est principalement relayée à partir de la Grande Guerre, ou en Roumanie, où l'influence de la pensée maurrassienne est réelle dans les années vingt dans les milieux intellectuels, mais diminue au profit de l'Allemagne durant les années trente.

\section{Le maurrassisme des Canadiens français : influence ou transfert?}

\section{Les limites d'une filiation idéologique}

Les travaux sur le maurrassisme au Canada français ont souligné la présence de l'imprégnation maurrassienne à partir de deux vecteurs. Le premier renvoie à une filiation par les textes et les références telles qu'elles ont pu être véhiculées par des articles, parus notamment dans la presse canadienne, 
L'Action française et L'Action nationale ou dans des correspondances. Le second vecteur concerne les échanges personnels eux-mêmes. Ils se déclinent selon deux registres : voyages effectués en France par des figures reconnues comme Édouard Montpetit et Lionel Groulx, ou moins en vue comme Paul Péladeau; immigration de maurrassiens français au Canada dont les symboles sont Gérard de Catalogne et surtout Robert Rumilly, arrivé en 1928.

À la lecture de ces travaux complétés par la lecture de sources imprimées, quelques remarques peuvent être formulées. La première concerne la teneur même de l'imprégnation maurrassienne et la question de sa définition : influence ou transfert. À cet égard, certaines réflexions proposées par Michel Espagne à partir de l'exemple franco-allemand peuvent être reprises, notamment lorsqu'il souligne qu' « un transfert culturel n'est pas déterminé principalement par un souci d'exportation » mais que «c'est la conjoncture du contexte d'accueil qui définit largement ce qui peut être importé ou encore ce qui, déjà présent dans une mémoire nationále latente, doit être réactivé pour servir dans les débats de l'heure ${ }^{30} \%$. Concernant le débat sur le maurrassisme au Canada français, on relèvera l'importance de l'ancrage français du maurrassisme pour Maurras et ses proches. Le sens et l'horizon de leur combat sont d'abord la France et le souci d'exportation n'existe guère chez eux. Du côté du Canada français, la démarche est comparable chez Groulx, d'abord soucieux de la défense de l'idée canadienne-française et des menaces qui pèsent, selon lui, sur son avenir. Interroger l'imprégnation maurrassienne de Groulx impose donc de mettre en relation la teneur de ses questions et de mesurer ce que le maurrassisme peut lui apporter.

Ce qui séduit Lionel Groulx dans le maurrassisme des premières décennies du $\mathrm{XX}^{\mathrm{c}}$ siècle, c'est d'abord sa préten- 
tion à incarner un catholicisme de combat, ce qui renvoie à une étape particulière du maurrassisme, où il s'est attaché, comme l'a montré Michael Sutton, à forger une alliance avec les catholiques. La chronologie de cet épisode est clairement identifiée pour la France : elle démarre avec le ministère Combes (1902-1905), prend son essor avec la fondation de la Ligue en 1905 sur fond de séparation de l'Église et de l'État et s'achève en 1926. Si le catholicisme de combat est un des identifiants des premières décennies d'existence de l'Action française, il ne saurait se confondre avec elle ni s'y réduire : le rejet violent de la III ${ }^{e}$ République, le monarchisme, l'antigermanisme, la lutte contre «l'Anti-France » entrent aussi dans la définition du maurrassisme. Sur un certain nombre de ces questions et en fonction de la conjoncture, l'AF peut se retrouver en phase avec des secteurs de l'opinion non maurrassiens mais sur lesquels ses analyses exercent une influence, par exemple, au sujet de la politique à mener vis-àvis de l'Allemagne. Les dirigeants de l'Action française en sont d'ailleurs parfaitement conscients et Maurras a forgé la notion de « compromis national ».

Où situer Lionel Groulx ? On remarquera d'abord que certains commentaires publiés au Canada avant le premier conflit mondial et favorables à Maurras sonnent assez juste et mettent l'accent sur l'ambiguité de la relation de Maurras à la foi catholique. Ainsi, l'abbé Élie-J. Auclair, commentant l'article du penseur martégal paru dans L'Action française d'août 1912, relève dans la Revue canadienne en janvier 1913 que Maurras " croit à la religion [...] comme à une force morale précieuse ; il croit au catholicisme comme à la religion traditionnelle de la France... Mais je doute s'il croit en Dieu. Il faut donc ne pas lire les yeux fermés ${ }^{31} »$. Lionel Groulx sait donc à quoi s'en tenir lorsque, 12 ans après son premier séjour (où il avait déjà assisté à un rassemblement d'AF), il re- 
vient en France en 1921-1922, rencontre ses principaux dirigeants et assiste au premier cours d'histoire de France à l'Institut d'Action française ${ }^{32}$. Par ailleurs, beaucoup plus que ses Mémoires, ses écrits contemporains ${ }^{33}$ et sa correspondance nous renseignent sur son état d'esprit et illustrent le résultat du travail de sape effectué par Maurras contre la démocratie libérale. Ainsi, dans un courrier bien connu adressé le 20 août 1927 à Jean Bruchési, neveu de l'archevêque de Montréal Paul Bruchési, Groulx souligne : " pour ma part, Maurras a contribué à me dégoûter de la démocratie ${ }^{34} »$. Le refus du monde moderne et de la Révolution française sont aussi un ciment profond comme l'écrit l'abbé à l'universitaire français et maurrassien Jean Houpert en 1927 : «Pour expliquer notre mutuelle sympathie entre royalistes français et Canadiens, $j$ 'ai déjà dit à quelques-uns de vos catholiques républicains : “ Entre un royaliste et nous, il n'y a que l'océan et cela se passe ; entre nous et un républicain il y a la mer de 89 et cela ne passe $\operatorname{pas}^{35}$ " ". Comme l'a souligné Pierre Trépanier, même si le providentialisme irrigue la pensée de Groulx et non celle de Maurras dont on connaît le goût pour Auguste Comte et les célèbres propos sur le « désespoir » considéré comme une "sottise absolue » en politique, il existe entre L'Action française de Montréal et celle de la rue de Rome un fond traditionaliste catholique commun nourri de Joseph de Maistre et de Frédéric Le Play. Il baigne l'univers groulxiste, disciple fervent de Pie X, alors qu'il n'est qu'un des éléments de la synthèse maurrassienne. Maurras est très clair sur ce point dans Le dilemme de Marc Sangnier lorsqu'il identifie les fondements de la pensée monarchiste, " "chrétienne" avant tout » et donc fondée sur le droit divin ou fondée sur «la nature et l'histoire». Pour Maurras, la chose est réputée de peu d'importance puisque " divisés sur l'origine des choses " ("L'un dit - Voici la loi de la nature... L'autre: Voici la loi de Celui qui a fait la nature») 
ces hommes «adhèrent aux mêmes vérités historiques et politiques ${ }^{36} »$. La différence est essentielle comme l'a montré Michael Sutton en soulignant les ambiguïtés et les limites des emprunts de Maurras au thomisme. Certes, le rapprochement entre le réalisme maurrassien et celui de saint Thomas renvoie aux distinctions thomistes entre les vérités de la Révélation et celles de la Raison et rencontre des points d'accroche avec une des grandes figures de la scolastique après saint Thomas, Francisco Suarez. Mais, comme l'a souligné Michael Sutton, une telle ressemblance est "superficielle", car pour saint Thomas « la loi naturelle ne peut se ramener à un ensemble de décrets qui ne se réfèrent au surnaturel que pour une justification extrinsèque ${ }^{37}$ ». Ces éléments n'ont sans doute pas échappé à Lionel Groulx qui a pu indiquer à Bruchési en 1927 : «Mais je n'ai jamais complètement gobé le cher Mâ̂tre », ce " grand esprit avec un grand trou par en haut ${ }^{38}$ ». Lorsque la condamnation est tombée, Groulx l'a sans doute regrettée, mais s'est soumis comme il l'a expliqué dans un courrier à Jean Houpert : "Nous avions pris l'habitude néanmoins de considérer L'Action française comme un journal de défense religieuse [...] Le pape a jugé que la doctrine maurrassienne contenait plus de périls que de promesses de vie. Nous nous sommes inclinés, catholiques de traditions et de convictions ${ }^{39}$. "

Ces quelques citations de Groulx, si on les sort du contexte canadien-français, invitent à s'interroger sur l'originalité de ce dernier. Elles font de Lionel Groulx un clerc pleinement de son temps qui pourrait, à bien des égards, être comparé à nombre de ses homologues européens.

Jusqu'à la veille du premier conflit mondial, les clercs français ont en majorité accepté ou toléré l'alliance proposée par l'AF entre maurrassiens et catholiques, à l'image notamment des jésuites de la revue Études. Une célèbre analyse de Pedro Descoqs intitulée «À travers l'œuvre de Charles Maur- 
ras ", publiée en 1909, livre dans sa conclusion des éléments essentiels : « Nous sommes amenés à conclure qu'entre le système de $\mathrm{M}$. Maurras et la doctrine catholique, s'il y a une opposition essentielle en matière de spéculation dogmatique et morale, il n'en est pas, à envisager les choses dans l'abstrait, d'irréductible sur le terrain pratique. Que des obstacles surgissent qui rendent illusoire l'accord avec lui dans l'action, il se peut : ces obstacles ne viendront pas de son système en tant que te ${ }^{40}$. »Effectivement, de multiples exemples attestent l'existence de cette alliance, des actions musclées des Camelots du roi lors des inventaires à la souscription lancée par le quotidien monarchiste à l'occasion de l'élévation à l'épiscopat de Monseigneur Penon ${ }^{41}$. Certes, des organes ou des intellectuels catholiques français, comme Maurice Blondel et Lucien Laberthonnière sont réservés voire hostiles à l'AF. Ils sont cependant minoritaires et pour certains en délicatesse avec la papauté (Laberthonnière est mis à l'Index en 1913). Cela n'empêche pas l'Action française d'être aussi mise sur la sellette à la veille du premier conflit mondial et la Congrégation de l'Index de conduire une instruction contre Maurras. Elle débouche le 26 janvier 1914 sur la condamnation de cinq ouvrages de Maurras et de la revue L'Action française. Pie X ne promulgue cependant pas le décret de condamnation et l'AF connait un sursis ${ }^{42}$.

En Belgique, les soutiens à l'AF sont nombreux jusqu'au début des années vingt. Présent outre-Quiévrain à la veille du premier conflit mondial par le truchement du travail effectué par Dom Besse, L'Université catholique ou la «Conférence du Jeune Barreau », le maurrassisme se développe surtout pendant le conflit et en sort très renforcé. En effet, audelà d'une imprégnation catholique et monarchiste susceptible, notamment en Wallonie, de trouver des relais, l'AF profite de la montée en puissance d'un sentiment nationaliste et 
germanophobe lié au traumatisme de l'invasion de 1914, aux frustrations nées du traité de Versailles, sans oublier les inquiétudes nées des succès du Parti ouvrier belge. À la différence de la relation qui préside entre la France et le Canada français, la guerre a fait naître, entre la France et la Belgique, une "convergence de situation » déjà pointée par Jacques Bainville dès novembre $1918^{43}$ et soulignée par Éric Defoort ${ }^{44}$. Elle n'existait pas avant 1914. Dorénavant des thématiques comme la germanophobie ou la mise en place d'une monarchie nationale supplantant une monarchie parlementaire sont communément développées et trouvent un relais dans le plus grand journal belge du temps, Le XX $X^{e}$ siècle. Maurras est d'ailleurs d'autant plus mis en avant " qu'il n'y a pas de penseurs belges sur des sujets de cet ordre ${ }^{45} »$. La fascination exercée par Maurras s'observe chez de nombreux intellectuels belges, ainés (Pierre Nothomb) comme cadets. Elle se retrouve chez de nombreux ecclésiastiques belges, de l'abbé anversois René-Gabriel Van den Hout, (homme de confiance du cardinal Mercier et fondateur de La Revue catholique des idées et des faits) au père Valère Honnay (qui multiplie les articles favorables à Maurras dans La Revue latine et La Revue générale). Comme en France, on relève chez ces clercs une défiance à l'égard de Maurras sur le plan religieux, mais elle est compensée par le bénéfice politique escompté d'une telle alliance même si l'abbé Van den Hout continue de militer en faveur d'un parti catholique. L'influence maurrassienne est enfin très profonde dans la jeunesse catholique. C'est ainsi que l'enquête organisée par les Cabiers de la jeunesse catholique en mai 1925 et adressée à « tous les jeunes intellectuels catholiques » sur les « maitres » des 25 dernières années plébiscite Maurras, arrivé en tête (174 voix sur 443 réponses) devant Paul Bourget (123) et Maurice Barrès $(91)^{46}$. C'est un véritable électrochoc pour les catholiques libéraux et les abbés démocrates qui se mobilisent dans 
le sillage de l'avocat bruxellois Fernand Passelecq et entreprennent une guerre de tranchée contre l'AF, laquelle trouve des relais en France à partir de la fin de l'année 1925. Un an plus tard, l'AF est condamnée et les catholiques sont sommés de choisir.

Pour l'essentiel, le choix passe par la soumission à Rome et, encore une fois, le Canada français n'échappe pas à la norme. Le débat sur la question de la condamnation de l'AF n'y a pas eu le même écho qu'en France ou en Belgique. On ne rencontre pas au Québec de mouvement de "renaissance littéraire catholique » et Cécile Vanderpelen a montré que Lionel Groulx lui-même ne paraît nullement avoir été influencé par des auteurs comme Henri Massis, Robert Vallery-Radot ou Pierre Nothomb, qu'il n'a jamais rencontrés et avec lesquels il n'a jamais correspondu ${ }^{47}$. Si la condamnation de l'AF enflamme le débat intellectuel en France et en Belgique, il n'existe pas d'équivalent au Canada français. Certains marquent une hésitation et le romancier Harry Bernard, décrit par Yvan Lamonde comme "maurrassien jusque dans ses romans", évoque dans l'édition du 7 janvier 1927 du Courrier de Saint- Hyacinthe le cas de certains « hommes cultivés » qui « sont assez désorientés et ne savent pas trop quelle attitude prendre à l'endroit de ceux qu'il considèrent, dans une certaine mesure, comme leurs maitres $^{48}$ ». Le Devoir d'Henri Bourrassa se contente de publier les documents importants de la Crise émanant du Vatican et des articles de La Croix ou d'Études ${ }^{49}$. L'Action française de Montréal n'a de son côté jamais analysé la pensée de Charles Maurra ${ }^{50}$ et la seule mention de la condamnation de 1926 s'effectue en janvier 1928 lorsque L'Action française de Montréal change de nom: "On sait les malheureux événements qui ont rendu suspect, par tout le monde catholique, le nom d'Action française. Nous n'avions rien en commun avec l'œuvre royaliste de Paris. Nous lui avions emprunté son nom comme, 
chez nous, beaucoup d'organes de presse qui adoptèrent un nom déjà usité en Europe. Il suffit que ce nom sonne mal aujourd'hui à des oreilles catholiques pour que nous en changions. Par simple déférence envers les autorités romaines, sans aucune pression ni invitation de qui que ce soit, mais de leur propre mouvement, les directeurs de notre Ligue ont décidé que la revue s'appellerait désormais L'Action canadienne-franfaise [...] Nos amis et nos lecteurs auront compris, une fois de plus, nous l'espérons, que notre foi de catholiques est au-dessus de tout ${ }^{51}$."

Ce texte a fait l'objet de controverses quant à son interprétation : à ceux qui considéraient l'absence de débats sur l'Action française comme "normale ", Catherine Pomeyrols oppose les « liens à cacher » qu'aurait l'Action française ainsi que les « contorsions et contradictions » de l'avis. Ainsi, « "nos amis auront compris" signifierait que "l'ennemi rôde" 52 ". Cette vision est appuyée par des citations emboitées dont on retient cet extrait : «Conserver à Dieu un peuple [...] nous paraît une œuvre qui l'emporte sur le rêve d'une grandeur politique et matérielle. Et voilà pourquoi nous ne nous arrêtons pas à cette entreprise de reconstruction française comme à une $\mathrm{fin}^{53}$.» Ce passage, loin de souligner la parenté entre les deux Action française, illustre selon nous la différence radicale d'inspiration entre l'AF maurrassienne et celle de sa supposée disciple montréalaise. Il ne s'est jamais agi pour Maurras d'accomplir le dessein de Dieu sur terre. La France pour lui n'est nullement le produit de la Providence mais celui d'une histoire millénaire, qu'il réécrit à sa façon. On a beau jeu d'opposer à la fin de l'extrait de la citation proposée par Catherine Pomeyrols : «Nous croyons à la mission apostolique du peuple canadien-français » quelques phrases du célèbre "Je suis Romain» du penseur martégal auxquelles il parait difficile de raccrocher la pensée de Lionel Groulx : "Je suis Romain parce 
que Rome, dès le consul Marius et le divin Jules jusqu’à Théodose, ébaucha la première configuration de ma France. Je suis Romain parce que Rome, la Rome des prêtres et des papes, a donné la solidité éternelle du sentiment, des mœurs, de la langue, du culte, à l'œuvre politique des généraux, des administrateurs et des juges romains [...] Et je n'éprouve jamais de difficultés à me sentir ainsi Romain, les intérêts du Catholicisme romain et ceux de la France se confondant presque toujours, ne se contredisant nulle part [...] Je suis Romain dans la mesure où je me sens homme : animal qui construit des villes et des États, non vague rongeur de racines [...] cet animal qui, voyageur ou sédentaire excelle à capitaliser les acquisitions du passé et même à en déduire une loi rationnelle $[. . .]^{54}$. » Il n'y a guère de fond commun entre les deux périodiques homonymes car sur le fond le clivage religieux est irréductible, plus encore sans doute qu'avec les catholiques belges ou français alliés à l'AF au nom d'un intérêt politique bien compris de la défense religieuse. Quand le voile se déchire, les hiérarchies réapparaissent de fait. L'Action française maurrassienne choisit bien entendu de privilégier son existence et son objectif qui est d'abord politique et passe par un changement de régime. Du côté montréalais, l'enracinement ultramontain conduit les clercs comme les laïcs de L'Action française à suivre le pape. On ajoutera que la condamnation de 1926 ne génère aucun phénomène de ralliement au célèbre «non possumus » de la rue de Rome et ne représente nullement un déchirement comparable à ce qu'il a pu être pour des catholiques maurrassiens, français ou belges, qui ont choisi Rome mais pour lesquels ce choix a été douloureux.

\section{Une pâle imitation estudiantine}

Le maurrassisme ne se définit pas seulement par une empreinte intellectuelle mais par un mode de sociabilité, une 
forme d'organisation (Camelots du roi) qui ont assurément marqué certains des jeunes Canadiens venus étudier à Paris durant les années vingt. Ils ont pu mesurer à quel point les militants d'Action française, tout en pouvant se présenter (avant 1926) comme des catholiques, des hommes d'ordre (la " querelle de l'ordre » est une des thématiques phares des revues de la Jeune Droite française de l'entre-deux-guerres), pouvaient provoquer et incarner le désordre par des bagarres régulières au quartier latin, agrémentées d'un abondant répertoire de chansons ("La France bouge ", "La Gueuse ») et de copieuses libations. La séduction a manifestement opéré. Jean Bruchési, qui a fréquenté des Camelots du roi à l'École libre des sciences politiques et à la Sorbonne, a laissé à ce sujet en 1929 un témoignage chaleureux : «Comment oublier que ces hommes ont imposé le cortège de Jeanne d'Arc, fessé Thalamas qui insultait la vierge de Domrémy, nettoyé le quartier latin en partie du moins, des mauvais éléments qui y travaillaient contre la vraie France, arraché la jeunesse universitaire à la révolution, et, un peu partout à travers le pays, chaque fois que c'était nécessaire, fait écho à la conscience nationale révoltée ? Ils ne craignent ni les coups ni la prison. Qui peut nier leur bravoure ${ }^{55}$ ? » Il reste à savoir si un tel modèle a donné lieu à une transposition.

Deux exemples permettent d'en mesurer la portée et les limites. Le premier concerne les membres de Jeune-Canada (ils sont une vingtaine) et leurs modes d'action. En 1933, le petit groupe d'André Laurendeau envisage d'attendre deux ministres à la sortie du train à Montréal et de leur administrer une fessée : le parallèle avec l'Action française parisienne est évident et l'hypothèse de l'imitation des Camelots du roi probable. Or, c'est Lionel Groulx en personne qui dissuade les jeunes gens de procéder ainsi et les invite à publier un manifeste $^{56}$. Les Jeune-Canada ne sont donc pas vraiment des Ca- 
melots du roi à la sauce canadienne. Sur le plan idéologique, un constat comparable peut être dressé à partir du dépouillement de la revue Vivre qui parait en 1934-1935. Elle rappelle un peu le ton de la jeune droite hexagonale d'inspiration maurrassienne de l'entre-deux-guerres ${ }^{57}$. La filiation avec le maurrassisme est d'ailleurs appuyée par la mise en exergue, dès le premier numéro, d'une citation de Léon Daudet : "Vivre, c'est lutter, qui n'a pas lutté n'a pas vécu ». On retrouve dans cette revue bien des éléments repérables dans des publication jeunes-droitières de l'Europe des années trente : culte de la jeunesse, vitalisme, affirmation de son identité et croyance dans la "révolution ${ }^{58}$ ». Le ton est donné par cette profession de foi : "La jeunesse est fatiguée de perdre son temps à écouter de vénérables fossiles lui nasiller qu'elle doit être docile et bien sage. Ce que nous voulons, c'est une destinée, en liaison avec notre caractère ethnique. Nous voulons revenir aux sources méditerranéennes et latines d'où nos sommes sortis [...] Bref, nous voulons refranciser notre moelle et nos cerveaux. Telles sont nos "positions". Réactionnaires devant le saxonnisme et l'aplaventrisme, qui firent de nous une "race de porteurs d'eau et de scieurs de bois", nous tendons les mains au soleil et à la vie. Si nous savons vouloir, demain, les hommes du pays de Québec seront des superbes et non des humbles ${ }^{59}$. " Les numéros de Vivre fourmillent de positions antidémocratiques et antiparlementaires : «Le parlementarisme se meurt, les députés sont morts ». Le remède préconisé est exprimé avec clarté à défaut de l'être avec élégance : "Quand on est affligé de constipation, on se purge [...] Ce qu'il faut, c'est la réaction ${ }^{60}$. " Le rejet du système canadien d'alors est abrupt et constant : "Quant à notre confédération, nous lui disons merde, parce que c'est elle qui nous a conduits où nous sommes ${ }^{61}$. " Si les rejets sont clairement identifiés, qu'en est-il du projet? Les maîtres à penser reven- 
diqués par la revue sont variés. Des étrangers sont mis en avant, notamment Péguy et Maurras mais aussi le Duce et Lénine puisque ces hommes se veulent les bolcheviques du nationalisme et affirment: «ici comme là-bas, la victoire appartiendra aux radicaux, aux partisans de la violence ${ }^{62} \%$. Du côté canadien, les choses sont en apparence simples: «Nous avons un doctrinaire: Groulx. Nous avons un chef de file: Asselin. Nous avons un journal : L'Ordre ${ }^{63}$. "Quant à l'objectif, il se combine à travers une double perspective. D'abord, le refus, revendiqué, d'un programme précis (qui par ailleurs n'existe guère) : «nous n'aurons jamais de programme mathématiquement et savamment défini en 12 points et 72 codicilles $^{64}$. $)$ La certitude réside dans la volonté de rupture et d'action. Jean-Louis Gagnon est catégorique : «La chute du régime est obligatoire [...] Quand un régime tombe, l'usage veut que ce soit grâce à une révolution. Et c'est le mot de la fin ou plutôt d'un recommencement. Révolution ${ }^{65}$. »

La prose de Vivre qui procède d'une triple inspiration groulxienne, maurrassienne et fascisante, le tout revisité par Lénine, est délicate à qualifier sur le plan idéologique. Le plus commode est d'y voir un avatar du fascisme, avatar dans lequel il serait commode de ranger Groulx, dont ces jeunes gens se revendiquent et qu'il a appuyés en leur écrivant pour les féliciter de leur refus d'être des "Français de conserve» et des « catholiques de conserve ${ }^{66}$ ». En fait, la phraséologie de Vivre signifie d'abord un activisme de plume, une volonté violente de sortir d'un confinement (les collèges sont mis en accusation) sans négliger une dose de provocation. Les critères $\mathrm{du}$ fascisme, tels qu'ils ont pu être définis notamment par Emilio Gentile ${ }^{67}$, sont difficiles à repérer dans une prose aussi confuse $^{68}$ où éclate, sous la plume de Philippe Vaillancourt, le véritable dessein de ces jeunes gens, bien éloignés des idéaux des jeunes fascistes européens de l'entre-deux-guerres : «Ici, 
à Vivre, nous ne voulons qu'une chose : que le peuple soit fidèle à ses curés, que les curés soient fidèles à leur race ${ }^{69}$. 》

Rapportée à la France et aux projets des jeunes maurrassiens des années trente, qu'ils aient ou non basculé vers le fascisme, cette citation permet de prendre la mesure du fossé existant alors entre les deux côtés de l'Atlantique. Il est par ailleurs significatif de constater que la revue canadienne ne se réfère pas à ses homologues françaises. La seule contribution hexagonale mise en avant est celle de René Dommange, député de Paris proche des ligues et participant à la sanglante manifestation antiparlementaire du Six Février 1934 qui, dans une lettre à Vivre, se cantonne à des généralités : «Les tendances, les espoirs des jeunes Français rejoignent ceux de leurs frères canadiens. L'aîné que je suis secondera de toutes ses forces les uns et les autres, heureux s'il peut un jour, à défaut de ces continents que cherchaient nos ancêtres, voir surgir de l'horizon les institutions qu'il rêve ${ }^{70}$. » Par la suite, le contact a été établi et relaté par Paul Péladeau. Il a rencontré les dirigeants de l'Action française, de Charles Maurras à Pierre Gaxotte, dîné chez la veuve de Jacques Bainville, mais aussi fréquenté les figures de proue des relèves maurrassiennes. Il a notamment livré un compte rendu instructif de ses entretiens avec Thierry Maulnier, le principal doctrinaire de la Jeune Droite. Les deux hommes ont notamment discuté de Maurras et bu « avec émotion » une bouteille de champagne «à la santé et à la longue vie de ce grand maitre de la pensée française ». Ensuite, après un long monologue de Maulnier sur sa tristesse devant l'état de la France, Péladeau l'a interrogé sur la question de «l'action», qui cristallise le basculement vers le fascisme de certains maurrassiens ${ }^{71}$. La réponse de Maulnier est significative de son engagement maurrassien retrempé à la fin des années trente après les désillusions de L'Insurgé (1936-1937) : “"L'action, 
l'action" répéta-il lentement, "il y a trente ans que Maurras fait de l'action. Si les jeunes n'avaient pas cet homme, ce très grand chef de soixante treize ans, pour commander leurs audaces, combien d'erreurs ils auraient commises avec leur tempérament, leur sang bouillant... Tant qu'il sera à nos côtés, nous serons dans l'action, mais dans l'essence de l'action... Ainsi nous n'assimilons pas action et programme, action et stratégie politique. Nous savons que les circonstances, les événements brutaux qu'un cerveau humain ne peut ordonner avant leur échéance, nous fourniront d'eux-mêmes les indications matérielles nécessaires au couronnement de nos idées. Une doctrine honnête, vraie et bien pensée est un principe assez puissant pour coordonner les faits à mesure qu'ils se produisent et pour leur donner la signification qu'ils doivent avoir dans l'ensemble. La doctrine est notre véritable arme politique" ». À Paul Péladeau qui lui demande si la jeunesse est " prête au combat » et s'il a été « décidé où et quand l'attaque devra porter pour implanter vos idées et placer vos hommes», Maulnier lui répond : «Le devoir de la jeunesse française, c'est surtout de perpétuer la tradition, c'est-à-dire de remettre la dignité dans la vie de la France en donnant aux valeurs intellectuelles, morales, spirituelles, leur vraie place; c'est de croire que les valeurs culturelles dominent les valeurs politiques et économiques qui n'en sont que l'application, la résignation tangible $\%$. Enfin, à une dernière question de Péladeau de savoir s'il croit à une "révolution » en France, Maulnier lui répond : « $\mathrm{Si}$, si, mais pas à une révolution tapageuse, pas à une révolution destructive. Nous croyons, si vous voulez me comprendre à la révolution de l'esprit [...] la jeunesse [...] veut construire, solide, pour des siècles, comme l'a toujours fait la France. [...] Chaque sacrifice sera une pierre du nouvel édifice de la nation française ». Et Péladeau de conclure : "Ces mêmes idées de lucide énergie, de réaction rai- 
sonnée je les avais entendu exprimer par Robert Brasillach, Claude Roy, Charles Mauban ${ }^{72}$.»

\section{La Nation, un épigone du maurrassisme?}

La Nation, "organe du séparatisme canadien-français » qui paraît du 15 février 1936 au $1^{\text {er }}$ août 1939, professe « une admiration sans borne pour ne pas dire un véritable culte» pour Lionel Groulx voyant «dans son œuvre la justification historique et conceptuelle de la thèse séparatiste qu'ils soutenaient ${ }^{73}$. " La Nation est peut-être aussi, durant les années trente, la publication qui peut être considérée, le plus sérieusement, comme un épigone de celle de la rue de Rome et de ses dissidents tentés par le fascisme, l'équipe de Je suis partout. Les travaux sur l'hebdomadaire québécois montrent cependant que les influences hexagonales sont diverses, de Gringoire à Candide, de L'Action française à Je suis partout. Ce dernier point est important car l'hebdomadaire, fondé en novembre 1930 et dont les rédacteurs les plus en vue sont de jeunes maurrassiens (Robert Brasillach, Lucien Rebatet) regroupés sous la férule de Pierre Gaxotte, est à partir du milieu des années trente attiré par le fascisme, fascisme entendu comme une révolution susceptible d'être propagée et acclimatée en Europe et hors d'Europe, en particulier au Canada français. $\mathrm{Si}$ pendant longtemps les quelques articles publiés sur le $\mathrm{Ca}$ nada français l'ont été à la page consacrée à l'empire britannique, Je suis partout publie à partir de janvier 1938 une page canadienne trimestrielle confiée à Dostaler O'Leary ${ }^{74}$, issu des Jeune-Canada et animateur en 1935 à Montréal avec son frère Walter d'un mouvement, les Jeunesses patriotes ${ }^{75}$. O'Leary développe dans Je suis partout les thèses séparatistes et profascistes qu'il défend aussi ponctuellement dans La Nation. Analysant le contenu de cette dernière, André J. Bélanger a souligné le «mimétisme ${ }^{76}$ » qui tient tant à la forme qu'au fond et 
qui renvoie à un phénomène d'importation de thématiques européennes de la seconde moitié des années trente au $\mathrm{Ca}$ nada français (clivage communisme/fascisme, éloge du fascisme italien, promotion du corporatisme, stigmatisation des fronts populaires), thématiques qui ont du mal à s'insérer dans le débat public canadien d'alors ${ }^{77}$. Il faut y ajouter, en suivant les travaux de Michel Lacroix, l'empreinte de la latinité, teintée dorénavant d'une sympathie affichée pour le fascisme italien et qui s'exprime à travers Front latin, une revue publiée à Paris à partir de 1935 et dont la cheville ouvrière est Charles Lesca, également actionnaire principal de Je suis partout. Au Canada, même si la revue Les Idées d'Albert Pelletier rend compte des activités de Front latin, c'est surtout La Nation qui est en première ligne ${ }^{78}$.

Le dépouillement intégral de La Nation permet de préciser et de dater l'ancrage maurrassien de l'hebdomadaire. À lorigine, même si le premier numéro s'ouvre sur un article de son rédacteur Pierre Chaloult consacré à Jacques Bainville qui insiste sur ses qualités d'historien, le compare à Voltaire et voit en lui « le plus lucide des intellectuels français au moment de sa mort $^{79}$ ", la moisson de références au maurrassisme est maigre. Au surplus, les articles consacrés à l'AF sont plutôt critiques. Dans une série de deux articles intitulée «Déclin de l'Action française ${ }^{80} "$, Jean-Marc Dufrenne, présenté comme professeur à l'Université Laval, livre de l'AF une histoire informée ( $\mathrm{y}$ compris de ses dissidences - Georges Valois - etc.) et il conclut par une analyse des plus pessimistes puisque le mouvement y est présenté comme en chute libre:

Au 6 février, qui apparaîtra sans doute à l'historien de l'avenir comme une date décisive dans la liquidation de la III ${ }^{e}$ République, il y a encore beaucoup de gens d'Action française parmi les manifestants. Mais, qu'ensuite les forces politiques se regroupent et s'organisent, 
ce sera ailleurs que le public même de droite ira chercher des chefs, chez les Croix-de-Feu, les Jeunesses Patriotes ou la Solidarité française. Quand, à la chambre des députés on parlera des « ligues fascistes », l'Action française ne sera même pas mentionnée. Que les jeunes à leur tour entrent dans l'arène des luttes politiques, ceux-là même qui rêvent d'un retour aux traditions nationales, iront fonder des groupes, des journaux nouveaux, Esprit, Réaction, l'Ordre nowveau, en dehors et souvent contre l'Action française, symptôme plus net encore, lorsqu'un prétendant, ou du moins un futur prétendant au trône, plus clairvoyant que ses prédécesseurs, voudra rallier les derniers partisans de la monarchie, ce sera autour du Courrier royal, et d'un programme où la corporation professionnelle aura repris sa place, qu'il tentera de le faire. L'Action française, donc, agonise. Elle ne représente plus, avec le conservatisme social le plus étroit, qu'une surenchère nationaliste qui n'a eu sa raison d'être qu'en temps de guerre, et où elle s'est figée $e^{81}$.

On ne commentera pas longuement l'exagération de ce texte quant à l'état de délabrement de l'AF ou les confusions opérées via des amalgames simplificateurs entre les différents rameaux des relèves spiritualistes des années trente. L'essentiel est ailleurs et tient dans la volonté de l'universitaire de discréditer l'AF comme modèle et comme référence auprès des lecteurs de La Nation:

Chose curieuse, elle garde peut-être plus de prestige à l'étranger, chez les peuples de langue et de culture française - Belgique, Suisse, Amérique du Nord - qu'en France même [...] Il faut une longue expérience des hommes et des choses de France pour se rendre compte qu'il faut chercher ailleurs un patriotisme moins exalté, mais plus profond, et un sens plus vivant des traditions françaises. Prendre comme modèle le sectarisme 
intransigeant de Maurras vieillissant, ne pourrait conduire qu'à perdre le contact avec les vivantes réalités, se raidir dans une attitude de défiance et de négation, et s'épuiser dans de stériles querelles de personnes ${ }^{82}$.

La Nation, de l'hiver 1936 à la fin du printemps 1937, soutient cependant Maurras, alors emprisonné, à travers quelques articles reproduits ${ }^{83}$. L'hommage le plus net émane de Berthelot Brunet, critique littéraire et collaborateur de L'Action nationale ${ }^{84}$ qui prend le soin de distinguer l'intellectuel et l'écrivain du mécréant ${ }^{85}$. Après avoir rappelé qu'il est « un des grands hommes de ce temps ", il stigmatise ses idées religieuses pour mieux mettre en valeur ses mérites littẹraires:

Les mésaventures religieuses de Charles Maurras ne m'intéressent pas. J'ai toujours su que sa justice était de ce monde $[. .$.$] Le Provençal ne saurait nous donner$ des leçons de catéchisme, ce n'est pas là son office. Les congrégations, le Pontife ont banni justement cet infidèle hors du temple: je ne sache pas qu'il ait jamais voulu s'agenouiller, s'il s'était fait le mercenaire de l'Église. Maurras n'est pas chrétien, il était opportun que l'Index le fit savoir aux têtes folles qui le tenaient pour un père de l'Église [...] Plus que la politique, les muses président à la vie du grand homme. Il rimait devant que de philosopher.

Et Brunet de conclure avec un lyrisme teinté d'amertume:

Je vois sourire Charles Maurras, je vois surtout la ride sourcilleuse du front. Son discours nous propose un ordre trop souvent sans amour. Ce Romain se montra trop grand, sa logique, sa phrase, ses mots sont une forte nourriture, délectable aussi ; nous rêvons à des fruits plus succulents et moins sains. Sommes nous trop faibles, frappés à jamais de langueur? ou lui trop dur? Le châtiment de Maurras, qui poussa la logique à des excès cousins du sophisme, c'est qu'il méritera le sort 
des autres : on écoute la musique, les grandes orgues, on néglige malgré soi les paroles du credo impitoyable. Rendons hommage, un libre hommage à Charles Maurras, Prince du Sang, Noble de vingt quartiers dans l'aristocratie de l'intelligence.

À partir de juin 1937, le ton et le contenu changent, sous l'impulsion de Marcel Hamel, dorénavant rédacteur en chef de l'hebdomadaire. La fréquence des articles consacrés à Maurras augmente très significativement, notamment pour saluer sa sortie de prison à l'occasion de laquelle Paul Bouchard prend la plume pour lui rendre un hommage appuyé $e^{86}$. Surtout, la prose de Hamel atteste d'une volonté de repenser et de réadapter le maurrassisme à l'aune des enjeux du Canada français. Le rédacteur en chef revendique, assume, discute et prolonge l'héritage maurrassien.

Marcel Hamel affiche expressément et publiquement son maurrassisme. Il raconte avec émotion sa découverte du maitre martégal et souligne le rôle d'éveilleur joué par Pierre Chaloult, décrit comme un " disciple forcené, quasi-anachronique ». Hamel veut faire partager « le plaisir ressenti au contact du dernier des Français, fumée d'or d'une prose athénienne dont je me suis grisé, tel un jeune satyre, sous les érables de mon village » et sa réceptivité :

Libre de toute attache, Maurras n'eut pas de difficulté à me gagner à ses thèses : il le ferait de vous également. Sa logique est trop pareille au collet du braconnier : il vous prend comme un lapin. Il est impossible de ne pas partager ses idées sur la révolution de 1793, source des malheurs actuels de notre mère-patrie. Son abattage de la démocratie et de son corollaire naturel, le libéralisme, est quelque chose de formidable : c'est la jument de Gargantua dessouchant d'un coup de queue la forêt de Beauce. Joseph de Maistre, en regard de lui, 
ressemble à un bambin qui voudrait anéantir une armée avec un tire-pois ${ }^{87}$.

L'admiration professée par Hamel a un fondement prioritairement politique. Le rédacteur en chef de La Nation valide en effet bien des analyses de Maurras et marque clairement sa différence avec les analyses de Jean-Marc Dufrenne publiées un an plus tôt. Marcel Hamel considère le diagnostic porté par Maurras sur la France de la Troisième République tout à fait fondé et rejette l'idée d'un déclin de l'AF :

Ce n'est pas de réussir qui compte, quoique le succès soit un gage de gloire, c'est d'avoir su raison garder, à l'instar des rois de France. Et Maurras, à qui est redevable dans sa plénitude le renouveau royaliste actuel ${ }^{88}$, trouve un change magnifique dans le spectacle de la France contemporaine, nation dégénérée où la semence d'Abraham a converti le sol de Jeanne d'Arc en Terre promise, où la synagogue a suppléé la cathédrale, où l'asiatisme barbare a remplacé les valeurs latines, où demain, par voie de conséquence aux immortels Principes, les eaux de la Seine se rougiront du sang des Français. Du fond de son cachot, Maurras n'a qu'à coller son œil sur le trou de la serrure et il voit en pleine lumière la confirmation de sa critique ${ }^{89}$.

Certes, Marcel Hamel admet l'antichristianisme de Maurras, mais c'est pour mieux rebondir :

Quoi qu'il en soit, l'exégète de Comte et ardent disciple de Sainte-Beuve reste un logicien maudit, et comme tel, notre foi catholique nous oblige à le renier solennellement. Rien ne nous empêche toutefois de choisir chez Maurras, après une purgation spirituelle de ses idées, ce qui relève de l'orthodoxie commune : car sa philosophie, inacceptable en bloc, quant à certaines parties, est riche, pour nous au Canada français, en possibilités créatrices. [...] En définitive, nous emprun- 
terons au publiciste royal cette méthode d'hygiène intellectuelle, rien que cela [ce qui est pourtant fondamental], qui lui a permis d'édifier une doctrine aux premiers abords chimériques, en l'an du Seigneur 1900, aujourd'hui de plus en plus à la demande pour assurer le salut public de la France. Nous pourrions emprunter aussi les deux idées de la décentralisation et du Politique d'abord, mais comme elles sont d'évidence même dans la thèse de nationalisme laurentien, je ne vois pas l'utilité d'en gloser. Ainsi, nous aurons accompli un travail analogue à Maurras qui a expurgé Auguste Comte à son profit personnel, comme Saint Thomas d'Aquin d'ailleurs, a dévalisé Aristote sur la route $\mathrm{d}^{\prime}$ Athènes à Rome ${ }^{90}$.

Rapportée au Canada français, cette perspective, selon Marcel Hamel, se décline de différentes façons. Elle lui permet d'abord de présenter Groulx comme un héritier de Maurras et plus généralement du nationalisme français. L'abbé aurait procédé avec lé penseur provençal comme ce dernier avec Comte. Le parallèle est percutant même s'il comporte des approximations, des raccourcis et des erreurs : «Groulx a été à Maurras ce que celui-ci fut à Auguste Comte. Il l'a choisi comme son maître. Il a institué sa revue L'Action française en empruntant le nom du fougueux journal de la rue de Boccador à Paris. Il a cité maintes fois Maurras au cours de ses nombreux discours et écrits sur les thèmes de la patrie canadiennefrançaise. Il a prononcé des conférences devant les Camelots du roi. Et lorsqu'en 1928 [sic], Rome a condamné le théoricien de la monarchie, l'abbé Groulx pour calmer les fiévreux a changé le titre de sa revue [...] Notre historien national continua le culte de la fidélité à Maurras - tout en compatissant sur ses erreurs et désirant qu'un jour ou l'autre, le philosophe athée se convertisse au catholicisme - car il lui devait beaucoup ${ }^{91}$. » Marcel Hamel ne se contente pas d'une filiation 
maurrassienne mais assure que Groulx a reçu une forte empreinte barrésienne: "Maurice Barrès exerça une influence formidable, non seulement sur la pensée de l'abbé Groulx, mais sur son vocabulaire, dans ses phrases. Et ceci est bien. De Maurras, il recevait le dépôt de la logique française, de la clarté française, de la rigueur française. Mais la sensibilité ? mais l'amour, mais la chaleur d'une mystique? Mais le lyrisme du poète? À Barrès revient l'honneur d'avoir déposé sur les épaules du maître le manteau du barde ${ }^{92}$.

Cette filiation est assumée. Marcel Hamel fait face à l'adversité et prend la plume contre Jean-Charles Harvey qui met en cause le maurrassisme de La Nation. Au début de 1938, Hamel, auquel Harvey a adressé son livre Art et combat, profite de l'occasion pour ironiser sur la superficialité de la lecture qu'a pu faire Harvey de Maurras et réaffirmer tant ses positions sur l'impossibilité d'une mise en place de la monarchie au Canada français que son rejet radical de la démocratie :

La discussion est amenée à propos de l'influence de l'Action française sur la jeunesse canadienne-française. M. Harvey, qui ne m'a pas l'air d'avoir usé ses lunettes sur l'Enquête sur la Monarchie, liquide ce régime en un tour de main. Son argument n'est pas si mauvais : il soutient que chez nous c'est une utopie de discuter d'une couronne et d'un trône. En quoi il a bien raison, quoique l'Unité ait un jour formulé un rêve irréalisable. Enfin! pour celui qui s'est trempé l'intelligence une fois dans la logique maurrassienne, il y a là un abîme dont il mesure toute la profondeur. Il reste donc la dictature. Elle a ses inconvénients, elle a aussi ses avantages, tout dépend de l'homme et du peuple. Hitler représente le tyran néfaste, et Mussolini le tyran transitoire et Salazar le tyran instable. Des trois, je préfère le duce parce qu'il est avec lui une monarchie puissante et héréditaire ; que 
demain il meurt, et le roi appellera un nouveau premier ministre : ce sera tout, peut-être mieux. En tout cas, à choisir entre la dictature et la démocratie, je ne choisis pas : je penche du côté de la dictature qui est encore une manifestation du bon sens sur la crapule et l'ineptie ${ }^{93}$.

L'attitude de Marcel Hamel n'est pas seulement défensive. Il entend interpréter et utiliser Maurras et manifeste ainsi une volonté explicite de transfert fondée sur une analogie méthodologique (on retrouve ici «l'empirisme organisateur ») et une vision historique globalisante :

Certes, son monarchisme est pour nous lettre morte ; mais la formule empirique dont il a usé pour amener Dieu et le Roi à la conclusion de sa géométrie contrerévolutionnaire est par une opération de l'esprit démontable de son cadre matériel et elle peut épouser un autre plan, la logique étant partout la logique. Ainsi appliquée à notre thèse, la méthode d'introspection maurrasisienne [sic], il surgit des rapports - théorème des triangles semblables - entre la Monarchie française et notre Nouvelle France, entre la Révolution et la Conquête, entre la République et la Confédération, entre un retour à la Monarchie et la création d'un État libre français en Amérique. Il ne s'agit pas dans les deux idéologies de simples coïncidences, mais de formidables cycles qui s'appellent les uns aux autres. Ainsi pour nous la conquête, comme la Révolution de 89 pour Maurras, est une vraie calamité. [...] L'exemple de Maurras est dans nos intelligences. De même, il continue d'asseoir la tradition de son pays dans les quarante rois qui en mille ans firent la France, non à partir de la coupure des institutions de l'an VIII, ainsi, nous devons jeter les ponts entre notre époque et les jours dorés de la Nouvelle France au-dessus de l'abîme de 1760. C'est ce que prêche depuis trente ans notre maitre Groulx. [...] 
En France, seul le Roi sauvera son peuple de l'anarchie révolutionnaire ; au Canada seul l'établissement d'un État libre français en plus d'assurer fortifiera la permanence de nos positions dans le Québec. L'implacable intelligence qui préside à la restauration de la Monarchie, préside de même à la création de l'État français, à moins qu'on ait perdu tout instinct de conservation $^{94}$.

L'allégeance proclamée à Groulx par les rédacteurs de La Nation, l'affirmation bruyante du maurrassisme de ce dernier et la proclamation de l'avènement d'un État français au Canada sous le signe de "l'intelligence » et de la raison ne suffisent pas à faire de Groulx un maurrassien et invitent plutôt à s'interroger sur les distances existant entre la pensée de Groulx et celle de ses jeunes et bruyants disciples. Comme l'a relevé avec justesse Julien Fabre, la question est posée de l'utilisation d'une méthode qui marque ses distances avec le providentialisme de l'abbé Groulx : « La Nation fait de l'idéologie maurrassienne son "catéchisme politique" car au service de la doctrine on ne met plus la foi mais la raison. $\mathrm{La}$ distanciation avec Lionel Groulx est alors effective, le séparatisme est réalisable, réaliste, une sorte de dernière révéla$\operatorname{tion}^{95}$. "

L'affiliation maurrassienne de Hamel n'est pas une simple allégeance car il prend certaines distances avec Maurras. En particulier, Hamel lui reproche ses positions vis-à-vis de l'Allemagne, égratignant au passage le rejet que le patron de l'AF éprouve à l'égard de Napoléon. L'empereur serait réputé pour Hamel avoir compris que l'ennemi était d'abord « Albion » et non l'Allemagne ou l'Autriche. Rapportée aux enjeux de 1937, la position de Maurras serait «illogique : il encense Mussolini et houspille Hitler dans le même article. L'Axe Rome-Berlin fatigue ses yeux de latin : le pays de Goethe constitue dans les inimitiés royalistes l'ennemi extérieur $\mathrm{n}^{\circ} 1$.» 
Pour Hamel, qui est ici dans la droite ligne de La Nation où les régimes fasciste, hitlérien, salazariste sont encensés (sans oublier Franco), Maurras "manque de politique extérieure ». Ainsi, «Il voit le salut de la France dans l'écrasement de l'Allemagne. Erreur tragique! Car une fois l'Allemagne écrasée, il ne restera plus que l'Italie seule contre un monde de barbarie. Henri Béraud, de Gringoire, est plus visionnaire que l'auteur d'Antinhéa qui demande : "Faut-il réduire l'Angleterre en esclavage ? » Là gît le nœud de vipères - Intelligence Service qu'il faut piétiner, écraser, malaxer de boue et de sang ${ }^{96}$ " La vision de Hamel fait songer à certaines analyses et aux amorces de dissidences repérées dans l'Hexagone au sein de la rédaction de Je suis partout où Robert Brasillach et Lucien Rebatet présentent leur fascisme comme le prolongement de leur nationalisme et cherchent à établir, selon leurs propres termes, une « ligne » fasciste et internationaliste ${ }^{97}$. L'attraction de Lesca pour la latinité et qui réclame des textes à son ami Paul Dumas se conjugue avec le philo-fascisme des collaborateurs de Je suis partout, intéressés de nouer des contacts avec des groupements étrangers réputés proches. C'est dans cette perspective qu'il faut comprendre la place faite par le canal de Dumas à O'Leary (contacté à la fin de 1937) même si elle n'est pas comparable à l'écho donné au rexisme, à là Phalange espagnole ou à la Garde de Fer.

La présentation et le contenu de La Nation évoquent davantage Je suis partout que L'Action française. La collaboration de Dostaler O'Leary à Je suis partout, motivée bien davantage par le philo-fascisme que par la défense culturelle de la latinité, est d'ailleurs saluée avec emphase par Roger Vézina : "À cette occasion, notre ami de Montréal mérite nos plus sincères félicitations. Je considère en effet comme un insigne hommage pour un journaliste du Canada français de pouvoir faire avaler sa prose par un hebdomadaire parisien d'une te- 
nue aussi parfaite que Je suis partout. Je souhaite qu'à l'exemple de M. O'Leary d'autres journalistes canadiens soient admis dans la phalange des collaborateurs bénévoles du miroir de la vie mondiale dans le monde journalistique ${ }^{98}$. " La suite du propos est très révélatrice de l'état d'esprit du collaborateur de La Nation: "Quand je dis miroir, ce n'est pas sans raison, depuis deux ans j'ai fait de Je suis partout mon journal de chevet. » Roger Vézina évoque ensuite sa découverte du rexisme, de l'intégralisme et d'un fascisme international... toutes choses que l'on retrouve dans La Nation entre 1936 et 1938.

Le maurrassisme de La Nation n'est pas seulement l'expression d'une fascination à distance. Le dépouillement de la correspondance reçue par Maurras montre en effet qu'un contact a été pris entre l'hebdomadaire québécois et le quotidien monarchiste. La minceur des sources interdit d'opérer des généralisations abusives, mais les données disponibles ne sont pas sans signification. C'est, logiquement, Marcel Hamel qui prend la plume en juin $1937^{99}$. Celui qui se présente comme un « très jeune confrère québécois » s'exprime avec une émotion touchante et naïve: "Je vous aime comme Montaigne aimait la Béotie (sic). Vous êtes le dernier des Français et nous, de « la Nation », vos fils spirituels d'outre-Atlantique, grâce à vous, nous sommes au Canada les amants fidèles de la France malheureuse. Perdus dans un sanctuaire lointain, nous continuons d'aviver la flamme dans les cœurs et dans les intelligences. L'impérialisme saxon, tant dans la culture et dans la politique, a depuis belle lurette conquis nos compatriotes, et la dégénérescence de notre vraie-mère patrie n'est pas pour encourager un retour, sentimental j'entends, aux dieux méditerranéen $s^{100}$. "Si Hamel se proclame catholique, il lève explicitement toute équivoque quant à la condamnation de 1926 et son attitude à son égard : "Je demeure un acharné disciple de 
vos idées quoique comme catholique, j'ai été obligé, par les menottes de l'opinion publique, de "vous renier solennellement" ".

Si cette position de son rédacteur en chef est un signe fort de l'orientation de La Nation vis-à-vis de l'Action française, un courrier de son secrétaire général adressé à la direction du quotidien monarchiste le 10 juin 1937 montre que la démarche de reconnaissance engagée est collective : «Messieurs, Vous nous obligeriez infiniment si en retour de notre journal que nous vous enverrons régulièrement chaque semaine, vous nous faisiez parvenir le vôtre. Espérant que vous ne tarderez guère à nous mettre sur votre liste d'échange, nous demeurons Vos tout dévoués. La Nation. ». La réponse de L'Action française tient dans une apostille sur la missive de Langlois : "avis favorable " avec la signature de Maurice Pujo ${ }^{101}$. On n'en sait guère plus. Il ne semble pourtant pas que la moindre collaboration s'esquisse entre les deux publications alors que les contacts existent entre La Nation et Je suis partout, dont certains des collaborateurs les plus éminents, comme Robert Brasillach ou Pierre-Antoine Cousteau, voient quelques-uns de leurs articles reproduits dans l'hebdomadaire montréalais ${ }^{102}$. À l'inverse, à partir du début de 1938, l'intérêt pour l'Action française, sans disparaitre complètement diminue très fortement. Marcel Hamel cesse d'écrire sur Maurras à partir de l'été $1938^{103}$ et si l'élection de Maurras à l'Académie française est saluée dans La Nation, cette dernière reproduit pour l'occasion l'article qu'a publié Brasillach dans Je suis partout ${ }^{104}$.

\section{Le Canada français des maurrassiens de l'Hexagone}

À la différence de la Ligue des Patriotes qui a tenté d'implanter, sans grand succès un comité au Canada français entre 1885 et $1888^{105}$, l'Action française n'a jamais cherché à 
s'établir au Québec. Force est même de constater le déséquilibre entre la France et le Canada français auquel les maurrassiens, de Maurras à aujourd'hui, se réfèrent peu, même si Aspects de la France a consacré un article à Lionel Groulx au milieu des années soixante-dix ${ }^{106}$. Concernant les premières décennies du $\mathrm{XX}^{\mathrm{e}}$ siècle, on ne saurait donc accueillir sans beaucoup de réserve ce propos de Lionel Groulx de $1922 \mathrm{mis}$ en avant par Catherine Pomeyrols : «celui qui tient la plume peut affirmer que les intellectuels du $\mathrm{n}^{\circ} 14$ de la rue de Rome se préoccupent vivement de l'avenir du Canada français ${ }^{107}$. " Des données objectives sont ici éclairantes. La consultation du Dictionnaire politique et critique de Maurras donne, en tout et pour tout, six articles sur le Canada français parus, le premier en 1908, le second en 1912 et les quatre autres entre 1934 et 1937 $7^{108}$. De son côté, Lionel Groulx ne fait l'objet d'aucune mention. Les archives de Charles Maurras, en particulier sa correspondance, sont également significatives : le dossier « Canada » réunit onze lettres, qui datent pour l'essentiel de 1937. On ne trouve pas de correspondant régulier de Maurras au Canada, y compris du côté français, ainsi que le montre l'unique lettre disponible de Robert Rumilly.

Abonné à L'Action fransaise de Paris, ce dernier écrit au «Maitre » qui a évoqué son livre Marguerite Bourgeoys. Les remerciements d'usage effectués, Rumilly entreprend de se présenter à Maurras qui ne le connaît pas, rappelle son itinéraire et fait le point sur son action à Montréal :

Je suis Action française et maurrassien jusqu'à la moelle des os. Lycéen d'Action française à Buffon, avec mon cher ami Marc Dejean de la Bâtie (tué à la guerre), puis à Louis le Grand (prix de philo à ce lycée, Malapert regnante), étudiant d'AF, ligueur du $\mathrm{XVI}^{\mathrm{e}}$ avec notre ami Baguenier-Désormeaux. Le trésor de ma bibliothèque est un exemplaire de Romantisme et Révolution ainsi dédicacé : «À monsieur Robert Rumilly, en souvenir 
des nuits de garde passées à l'imprimerie d'Action française ». Fils d'officier - et d'une famille toute militaire mon oncle Vayssière a commandé la garde républicaine -, j'ai fait de belles études prometteuses, j'ai fait la guerre et j'en suis sorti avec des galons et, ma foi, de belles citations de fantassin (classe 17). Ayant perdu mon père de bonne heure (commandant Rumilly, ancien élève de choix de Foch, mort empoisonné au Tonkin en 1910), j'aurais été tenté par l'anarchie intellectuelle à quoi l'on nous conviait (j'étais boursier de l'État) si je n'avais adopté le maître Maurras et les doctrines - les doctrines d'AF - auxquels je dois, après mes parents, à peu près tout. J'ai vécu intensément, et vous savez ce que cela veut dire, toutes les heures de l'Action française. Mais j'en ai eu assez d'aller toujours aux enterrements des nôtres (et le dernier mon camarade Marcel Langlois tué depuis mon départ) et jamais aux enterrements des adversaires. Trop de choses et trop de gens m'ont dégoûté. Malgré vous, malgré vos consignes, j'ai désespéré de jamais voir dans mon pays, dans ma classe sociale, le redressement pour lequel nous avons travaillé. Si j’avais prévu seulement le 6 février, je serais resté. Mais j'ai fini par partir dégoûté de la vieille France pour la nouvelle France. À quelque chose, malheur est bon. À mon rang, avec mes petits moyens, je me suis livré ici à une œuvre française et je dois vous l'écrire, puisque je le crois, avec plus de confiance dans le succès final que je n'en avais en France même. C'est moi qui ai conseillé au vaillant TRAVAILLEUR de Worcester ${ }^{109}$ d'entrer en relations avec vous. Je suis d'AF. $\mathrm{Ne}$ le cache jamais. J'en parle librement chez mes amis les Pères du Saint-Esprit, chez mes amis les pères oblats, chez mes amis les pères dominicains. J'ai donné des conférences sur vous à Montréal ${ }^{110}$.

Ce courrier de Rumilly est unique en son genre et ne débouche nullement chez Maurras sur une volonté de déve- 
lopper des relations ou de faire diffuser ses thèses outre-Atlantique. La chose ne l'intéresse guère. Le contenu de la prose maurrassienne sur le Canada n'en est pas moins chaleureux, riche d'intérêt quant aux représentations véhiculées sur ce dernier et fort instructif quant aux implications politiques qui peuvent en être retirées. Lorsque Charles Maurras évoque le Canada français, il pense d'abord à la France, à « ce magnifique rameau de notre race et de notre langue qui, par delà la Mer océane ne cesse de produire ses feuilles et ses fruits ». Il $\mathrm{y}$ voit « un des hauts lieux du nationalisme français $[. .$.$] trois$ fois fidèle à sa langue, à son sang, à sa foi » et «appelé aux initiatives majeures de l'ordre intellectuel et moral ${ }^{111} »$. L'admiration du penseur martégal pour le Canada français est profonde. Elle s'attache d'abord à l'action entreprise pour la défense et la perpétuation de la langue française. Il nourrit son propos d'exemples précis, en particulier celui du vocabulaire sportif: "Nous avons dans les archives d'Action francaise, fortement illustré par Lucien Dubech, un témoignage admirable de ce dévouement à la langue des pères : c'est la traduction mot à mot et complète de tout l'affreux vocabulaire des sports, universellement britannique, en beau et bon français, soit médiéval, soit moderne, soit contemporain. Quand nos coureurs et nos athlètes comprendront-ils que le Canada leur donne l'exemple de parler français ${ }^{112}$ ? " Cette admiration se retrouve trois ans plus tard lorsque Maurras évoque en mars le Deuxième Congrès de la langue française prévu à Québec au début de l'été 1937. Commentant le «cas privilégié et magnifique de l'expansion du français au Canada », Maurras s'exclame : « Un seul sentiment est possible : l'admiration, celle qui est due à près de deux siècles d'une fière et féconde fidélitén $^{113}$. " Maurras qui relit à sa façon l'histoire canadienne rend également un hommage appuyé à l'action du clergé, aux « hommes noirs»: ils «fondaient des paroisses et des écoles, ils 
rétablissaient foyers, langage, religion, disputaient comme ils disent "l'âme française" à ses "voleurs", la rendaient à ellemême et fédéraient de plus en plus les belles agglomérations qui se sont si bien développées en soixante-quinze ans, que de toutes parts, on y travaille à fonder, par comités et souscomités, des délégations au Congrès de Québec ${ }^{114}$.» En fait, ce que Maurras voit surtout dans le Canada qu'il décrit et propose à ses lecteurs, c'est l'image d'un pays qui a su préserver et développer la tradition et n'a pas été abîmé par la modernité. Cela lui permet d'idéaliser un Canada opposé aux États-Unis dans des termes lyriques : «Heureux pays! Vous avez une foi, une langue, un esprit de famille, une paysannerie, des mours... Où n'irait une race humaine avec de tels atouts ? Comparez la stabilité, la fécondité de vos foyers à l'instabilité, à la stérilité du foyer américain. Votre moralité à la criminalité des autres. Votre fidélité, votre unité religieuse, à leur morcellement, au pullulement de leurs sectes et de leurs temples! Votre puissance et courageuse continuité ethnique et linguistique à cette mosaïque d'immigrants de tous lieux et de tous pays ! Comparez vos champs, même vos forêts, à l'industrialisme dont vos voisins sont prisonniers, même la charrue à main. Un seul élément paraît militer contre vous, c'est leur nombre. Mais l'armée du roi des rois comptait des centaines de milliers d'hommes, et les bataillons de Miltiade, de Thémistocle et de Léonidas ne faisaient qu'une poignée : ils l'ont emporté pour les siècles. Les mécanismes de l'histoire sont hérö̈ques ${ }^{115}$.»

Pour autant que l'on puisse en juger, le discours maurrassien des années trente est assurément en décalage avec l'état d'esprit dominant des dirigeants de l'ex-Action française canadienne, l'abbé Groulx en tête. Certes Maurras avait pris le soin de balayer les craintes des Canadiens français qu'il a pu recevoir (aucun nom n'est cité mais Louis D. Durand, an- 
cienne figure de L'Action française canadienne des années vingt ${ }^{116}$, lui a écrit $\left.{ }^{117}\right):$ " Il arrive aux Canadiens français de se juger avec sévérité et d'adresser à leurs organisations intérieures ces nobles reproches qui reviennent à dire que, si la défense ou la propagande nécessaires ont été faites, elles auraient pu être poussées plus loin ou conduites avec plus d'énergie... Reproches de lutteurs! Scrupules de héros !118 " Le lyrisme de Maurras en 1937 contraste avec ses craintes de 1912 où il s'inquiétait du développement de relations francocanadiennes sous l'égide de la République : "Ce n'est pas la race canadienne-française et catholique qui en profitera. Le Grand Orient de France a ses succursales au Québec. Les idées révolutionnaires y possèdent leurs véhicules qui sont tout prêts : journaux, revues, librairies, théâtres, bibliothèques ; bientôt même on peut dire qu'un public est formé pour accueillir ces laissés pour compte de l'Europe civilisée ${ }^{119}$."

La satisfaction affichée par Maurras contraste avec le ton de la brochure du jésuite Alexandre Dugré (Notre survivance francaise) et celui du discours prononcé par Groulx au congrès de 1937 : «L'histoire gardienne des traditions vivantes ", dans lequel il critique vivement le Québec et en particulier sa classe politique pour l'insuffisance de son action visà-vis des minorités ${ }^{120}$. L'article de Maurras suscite surtout une réaction négative de Marcel Hamel qui marque son désaccord et réclame à Maurras dans une « supplique » d'intervenir de nouveau et ce dans le sens de ses disciples autoproclamés: "Vous avez écrit un article sur le prochain congrès de langue française et qui eut ici un extraordinaire retentissement. Ces panathénées, je voudrais vous le crier, n'auront rien de français et de latin. Il s'agit d'une démonstration sinistre où s'affirmera au son des trompettes, un féal hommage à l'Angleterre. Aussi je suis peiné de l'esprit de cet article. Je ne reconnais pas l'auteur de «Politique d'abord». Vous accordez à 
notre culte du langage de France une importance qui n'existe pas sans le substrat des institutions politiques et économiques. Il est vrai que vous avez pour vous l'ignorance du mouvement nationaliste québécois dont vous pouvez lire le manifeste au bas de cette page : pour un État libre français en Amérique. » Du constat, Marcel Hamel passe aux recommandations :

Vous pourriez conseiller ces messieurs de l'Académie à l'occasion de leur visite dans nos murs. [...] Prenezles de nous rappeler nos responsabilités françaises en Amérique ; persuadez-les de ne pas se préoccuper du problème louisianais - devenu depuis 1760 un problème nègre - ; montrez-leur que la civilisation française n'a pas de chances de survie au Canada ailleurs que dans le jardin des Laurentides, pas dans les forêts de la Nouvelle-Angleterre, pas dans les prairies de bisons et de totems, pas sur les terres hostiles de l'Ontario, mais dans le territoire du Québec [...] Écrivez cet article, je vous prie et vous aurez à votre insu proclamé un séparatisme spirituel avant-coureur de l'autre : ce sera sur le plan américain une adhérence nouvelle à votre «Enquête sur la Monarchie». Vous nous aurez alors procuré une immense et débordante joie d'homme.

Cette lettre de Marcel Hamel, dont on ignore si elle a suscité une réponse de Maurras, appelle une double remarque. On constate d'abord que Maurras est remis en cause au nom de ses propres principes et invité à se rétracter, ce qui n'est guère dans sa nature. Mieux encore, il est prié d'intervenir dans un débat extra-hexagonal. Hamel ignore que Maurras a reçu quelques mois plus tôt de la part de Louis D. Durand un très long courrier dans lequel l'avocat, qui avait participé en mars 1922 à l'enquête de L'Action française de Montréal sur "l'avenir du Canada français ${ }^{121}$ ", proposait une analyse diffé- 
rente de la sienne, notamment pour ce qui concerne les minorités francophones hors Québec ${ }^{122}$. Louis D. Durand soulignait la « formidable leçon qui nous vient de l'État de la Louisiane en immense majorité anglo-saxon et situé si loin, si loin du foyer français de Québec [...] Quel exemple et quelle leçon pour le seul gouvernement français et catholique d'Amérique du Nord, celui de la vieille province de Québec, comme pour tous les gouvernements municipaux et scolaires de cette province française. » Surtout, comme Marcel Hamel, Louis D. Durand excipe d'une fidélité maurrassienne qu'il exprime avec chaleur: «Depuis longtemps je cherche un moyen de vous dire mon admiration, ma reconnaissance et mon affection. Vous êtes mon ami depuis mes jours de Belles-Lettres 19081909. C'est à M. Omer Héroux que je dois le bienfait de vous avoir connu. Frontières ${ }^{123}$ m'a permis de vous rendre publiquement le témoignage de ce que je vous dois, par une simple signature, hélas, mais donnée avec quelle joie, et ma lettre comme ma demande de ce jour, puisqu'elle nous rendrait service, si elle était agréée, est peut-être encore une façon plus directe, plus personnelle, plus appuyée, de vous dire en quelle profonde estime je tiens le prisonnier de la Santé parce que je le prie de nous aider à " recomposer" notre nationalité. » $\mathrm{Ce}$ dernier point est fondamental, car Louis D. Durand, comme Marcel Hamel, réclame au "maitre » son avis et son appui : «Vous êtes le gardien de l'espérance française dans le monde à l'heure actuelle. Il est naturel que de partout nous nous tournions vers vous. C'est la rançon de votre vigilance et c'est ma seule excuse, à venir vous relancer, jusqu'à la Santé, vous que je lis depuis vingt ans. Si l'on veut décider les Français à se sauver, il faut les résoudre à se penser ». Et Durand de suggérer comme Hamel des pistes de réponse à son interlocuteur : «M. Maurras, dites-nous que nous ne resterons Français que si nous sauvons la langue, oui, mais que le meilleur moyen de 
sauver la langue c'est de commencer par sauver toutes les conditions matérielles qui pourraient en assurer le rayonnement : écoles, presse, musées, reliques, monuments, affiches, chansons, tout ce qui peut nous relier de façon vivante et presque tangible à notre passé en nous rattachant à plus profond, à plus lointain que nous-même et le temps présent. »

Ces deux correspondances, qui sont autant la marque d'allégeance que de dépendance intellectuelle, invitent à différentes remarques. Leur faible nombre interdit de les considérer comme représentatives, mais leur existence souligne la relation étroite et ancienne existant entre certains publicistes canadiens-français et Maurras. Tous deux s'illusionnent cependant profondément sur ses intentions et ses supposées réactions dans un tel débat. Maurras n'y est pas intervenu pour deux raisons majeures. La première est une raison de principe : Maurras refuse depuis les années vingt d'être une sorte de chef d'une quelconque "internationale blanche ${ }^{124}$ » et se garde bien de prendre des positions concernant des débats internes à l'intérieur de mouvements nationalistes autres que l'Action française de même qu'il n'entend prodiguer aucun conseil. Cette attitude, déjà observée pour la péninsule ibérique, se confirme ici. Elle se double ici d'un autre élément pointé avec justesse par Charles Chicoine, qui a rencontré le «Maître de Martigues » en 1935 : «Charles Maurras avait une connaissance surprenante ou au moins des opinions très précises sur le Canada français ${ }^{125} "$. Si on songe à la psychologie du personnage et à son mode de raisonnement intellectuel, il apparaît peu probable que deux courriers de disciples chaleureux mais inconnus de lui soient de nature à le faire évoluer en profondeur sur un tel objet. On constate d'ailleurs qu'audelà de Maurras lui-même s'opère à la fin des années trente dans la nébuleuse maurrassienne française à l'égard du $\mathrm{Ca}$ - 
nada un raisonnement combinant décalage dans le temps et analogie.

Paul Péladeau cite en particulier une lettre que René Vincent, grand ami de Maulnier et directeur de Combat (une des principales revues de la Jeune droite) lui a adressée depuis les armées et qui l'a "profondément ému » : "J'ai toujours constaté combien étaient proches la vie de ces Français d'autrefois que sont les Canadiens d'aujourd'hui et celle des Français d'ici, non telle sans doute que la laissent imaginer parfois notre littérature et notre politique, mais telle qu'elle est demeurée dans les familles et dans les provinces. Je voudrais, si je n'étais pas retenu dans les sous-sols de la ligne Maginot, vous faire retrouver ces correspondances profondes qui existent entre nous et que dissimulent souvent des agitations superficielles et bruyantes qui ne sont pas celles de la vraie France, mais qui finissent pas la corrompre ${ }^{126} »$. En langage maurrassien, le Canada serait bien le dépositaire à part entière d'un "pays réel » dont il existerait l'équivalent en France, malgré la "corruption » à l'œuvre. La leçon est bien reçue de l'autre côté de l'Atlantique à lire certains comptes rendus de l'ouvrage. Si celui publié par L'Action nationale est favorable mais prudent ${ }^{127}$, Maurice d'Auteuil dans Le Devoir est beaucoup plus engagé et reprend à son compte les diagnostics proposés pour tirer des enseignements de la défaite de 1940 et des précautions à prendre pour le Canada français : «La France doit sa douloureuse éclipse à la désunion de ses enfants devant les ennemis intérieurs et extérieurs [...] Elle la doit aux germes toxiques que l'excès de la maladie parlementaire avaient injectés comme autant de principes de mort jusque dans les parties les plus saines en apparence de la Nation. Lire "On disait en France" [...] c'est assister, par procuration, à l'aboutissement inévitable des diverses maladies 
qui nous travaillent, si nous ne leur portons pas remède avant qu'il ne soit trop $\operatorname{tard}^{128}$.»

\section{$* * *$}

Importants avant la condamnation de 1926, brisés un temps par cette dernière, les échanges entre Canadiens français et Français de sensibilité nationaliste et catholique ont repris à la veille de la guerre, facilités sans doute par la levée des sanctions décidées par le Vatican ${ }^{129}$. La défaite de 1940, le ralliement de l'Action française au régime de Vichy et l'opprobre qui a suivi le procès de Maurras en 1945 ont brisé net le rapprochement esquissé par le reportage de Péladeau. Par la suite, comme l'a montré Pierre Trépanier, à quelques exceptions près ${ }^{130}$, le silence domine et Maurras et l'Action française sont pour leurs anciens sympathisants canadiens-français rangés parmi des souvenirs encombrants. Du côté français, le choc de l'épuration passé, le maurrassisme a refait surface sans jamais retrouver l'écho qu'il avait avant la guerre. Pourtant, que ce soit dans les sphères journalistiques, étudiantes (renouveau des étudiants royalistes au début des années cinquante), littéraires (avec la Table ronde, les Hussards), politiques voire activistes (OAS-Métropole) l'Action française a continué sa route. Elle n'a jamais recroisé celle du Canada français, grand absent, pour autant que l'on puisse en juger, des contacts noués avec l'étranger. Ainsi, lors d'un numéro spécial d'hommages des Cabiers Charles Maurras pour le dixième anniversaire de sa mort, on ne trouve aucune signature provenant du Canada français parmi les «hommages d'au-delà de nos frontières ${ }^{131} »$.

Les liens entre le maurrassisme et le Canada français sont donc l'affaire d'une rencontre, d'un moment, d'une influence davantage que d'un transfert. La relation entre les deux pôles est très déséquilibrée et sur chacune des rives de l'At- 
lantique, les attentes ne sont pas les mêmes. Si du côté canadien-français, l'Action française de la rue de Rome constitue un réservoir de références, de thématiques voire un exemple à suivre, éléments qui inviteraient à s'interroger sur l'existence d'un transfert, cette vision globale est tempérée par deux données essentielles.

La première est que Groulx et ses amis ne puisent que dans une partie du corpus de l'Action française soit la composante traditionaliste catholique, la volonté de réagir pour reforger une identité jugée menacée. Qu'en est-il de cette empreinte sur le fond ? Sur le premier thème, l'Action française parisienne n'est pas particulièrement originale et l'Action française canadienne mobilise fort logiquement d'autres références issues du milieu catholique, en particulier le quotidien La Croix. Quant au second, il parait difficile de considérer que Lionel Groulx ait de la nation et de la défense de son identité une conception analogue à celle de Maurras. Certes, les deux pensées ont en commun un certain nombre d'adversaires mais cultiver des figures identiques de l'ennemi ne forge pas un projet positif. Il n'y a d'ailleurs pas chez Lionel Groulx ni même véritablement par la suite chez les rédacteurs de $L a$ Nation, à l'exception notable de Marcel Hamel, de démarche entreprise pour repenser et acclimater la doctrine maurrassienne. Le phénomène est logique car des pans entiers et fondamentaux de cette dernière sont étrangers aux Canadiens français, bien éloignés de leurs préoccupations et de leurs horizons : monarchisme, questions internationales liées à l'Allemagne et au traité de Versailles, lutte quotidienne contre la Troisième République et son personnel. Il faut ajouter l'attitude de l'Action française de la rue de Rome et de Maurras lui-même qui tout en se félicitant de voir l'AF rayonner à l'étranger ne cherche nullement à être le chef d'une quelconque internationale des nationalistes ni même d'une inter- 
nationale latine. L'horizon de Maurras est d'abord la France et la latinité dans laquelle il inclut le Canada français ${ }^{132}$. C'est d'ailleurs beaucoup plus ce dernier qui l'intéresse que l'Action française de Montréal et ce pour une raison évidente à ses yeux : il s'agit du prolongement d'une France traditionnelle destinée de ce fait à être défendue. Le "pays réel » idéal de Maurras, celui qui ressort de sa vision du passé joliment qualifiée par Michael Sutton de "conte habilement déguisé en histoire », renvoie à un âge d'or représenté par le XVII siècle français ${ }^{133}$. Il reste à savoir si cette vision du penseur martégal correspond à celle de ses supposés disciples canadiens où s'il n'existe pas un malentendu entre les deux rives de l'Atlantique. Que des Canadiens français aient été influencés par Maurras et l'Action française de Paris relève de l'évidence. Cette imprégnation, sauf exception individuelle, comme le montre l'exemple de Marcel Hamel, n'est cependant pas assimilable à un transfert culturel et politique.

\section{NOTES}

${ }^{1}$ Éric Bédard, « Penser le conservatisme », Recherches sociographiques, vol. XLVI, $\mathrm{n}^{\circ} 3$ (2005), p. 453-471 [numéro dirigé par Gilles Gagné et intitulé Le Canada français, son temps, sa nature, son béritage].

${ }^{2}$ Voir à ce sujet la note de lecture engagée de Pierre Trépanier, « Le renard ayant la queue coupée ou La luxuriance des études groulxiennes (1999-2003)", Mens, vol. IV, n 2 (printemps 2004), p. 273-307. Se reporter aussi à Robert Boily, dir., Un béritage controversé. Nouvelles lectures de Lionel Groulx, Montréal, VLB, 2005, $185 \mathrm{p}$.

${ }^{3}$ Voir son ouvrage The Passionate Debate. The Social and Political Ideas of Quebec Nationalism, 1920-1945, Montréal, Véhicule Press, 1991, p. 82-89.

${ }^{4}$ Voir notamment le chapitre VIII « "L'Action française" de Montréal et de Paris » de son ouvrage intitulé Histoire sociale des idées an Québec (1896-1929), Montréal, Fides, 2004, p. 189. La présence de Barrès dans ce chapitre consacré à l'Action française pose problème et est facteur de confusion. Si l'auteur du 
Roman de l'énergie nationale est avec le penseur martégal un des deux grands doctrinaires du nationalisme français, leurs fondements intellectuels comme leurs perspectives sont sur bien des points opposés, quelles qu'aient été par ailleurs leurs relations d'amitié et d'estime. L'édition de leur correspondance - Maurice Barrès et Charles Maurras, La République ou le Roi. Correspondance inédite (1888-1923), réunie et classée par Hélène et Nicole Maurras, commentée par Henri Massis. Introduction et notes de Guy Dupré, Paris, Plon, 1970 ainsi que de nombreux passages des Cabiers de Barrès en rendent compte. À lire Yvan Lamonde et à compter les occurrences de Barrès et de Maurras dans ce chapitre, il semblerait que le premier ait exercé une influence supérieure au second. Or, si en France on a pu parler d'un maurrassisme après Maurras, il n'a pas existé de "barrèsisme » en dépit des influences multiples que le romancier nationaliste a exercées.

${ }^{5}$ Voir en particulier de cette dernière, «Les intellectuels nationalistes québécois et la condamnation de l'Action française ", L'ingtième siècle. Revue d'bistoire, 73 (janvier-mars 2002), p. 83-98.

'Pierre Trépanier, «Le maurrassisme au Canada français », Les Cabiers des Dix, $\mathrm{n}^{\circ} 53$ (1999), p. 167-233.

${ }^{7}$ Elle a été ébauchée à l'occasion d'une conférence à l'Université d'Ottawa en mars 2006. Qu'il me soit permis de remercier mes collègues É.-Martin Meunier et Michel Bock de m'avoir invité à prononcer cette conférence ainsi qu'Yvan Lamonde avec lequel le débat a été fructueux.

${ }^{8}$ On songe notamment à leur programme de recherche développé dans Michel Espagne, Michael Werner, "Transferts culturels franco-allemands ", Revue de synthèse, 1988, n 2, p. 187-194.

${ }^{9}$ Hans-Manfred Bock, «Transaction, transfert et constitution de réseaux. Concepts pour une histoire sociale des relations culturelles transnationales ", dans Hans-Manfred Bock et Gilbert Krebs, Échanges culturels et relations diplomatiques. Présences françaises à Berlin au temps de la République de Weimar, Paris, PIA, 2004, p. 11.

${ }^{10}$ Ibid., p. 13.

${ }^{11}$ Sur ce point, se reporter à Guillaume Gros, Philippe Ariès (1914-1984). Un traditionaliste non-conformiste: de l'Action francaise à l'École des bautes études en sciences sociales, thèse de doctorat d'histoire du vingtième siècle, IEP de Paris, 2002 , notamment la quatrième partie. 
${ }^{12}$ Un débat mettant face à face notamment Jean Caunes et Hilaire de Crémiers organisé à l'occasion du centenaire de la naissance de Maurras a été reproduit dans le $\mathrm{n}^{\circ} 11$ de Jeune Révolution sous le titre "Actualité de Charles Maurras » (p. 14-17). Sur cette organisation clandestine née en 1961, dirigée par le général Salan et qui s'est efforcée de lutter par tous les moyens (y compris le terrorisme) pour le maintien de l'Algérie française, nous nous permettons de renvoyer à Olivier Dard, Voyage au cour de l'OAS, Paris, Perrin, 2005, 423 p.

${ }^{13}$ Victor Nguyen, Aux origines de l'Action française. Intelligence et politique à l'aube duXX' siecle, préface de Pierre Chaunu, Paris, Fayard, 1991, 958 p. ; Michael Sutton, Charles Maurras et les catboliques franfais 1880-1914, Paris, Beauchesne, 1994, 365 p. ; Bruno Goyet, Charles Maurras, Paris, Presses de Sciences Po, 2000, 306 p. ; Stéphane Giocanti, Charles Maurras : le chaos et l'ordre, Paris, Flammarion, 2006, 575 p. et Domenico Fisichella, La democrazia contra la realta. Ilpensiero politico di Charles Maurras, Rome, Carocci editore, 2006, $192 \mathrm{p}$.

${ }^{14}$ Michael Sutton, Charles Maurras..., p. 7.

${ }^{15}$ Jacques Prévotat, Les catholiques et l'Action française. Histoire d'une condamnation, Paris, Fayard, 2001, p. 503. La ligue compte selon lui à l'automne 1927 30000 membres.

${ }^{16}$ Jean-François Colas, Les droites nationales en Lorraine dans les années trente: acteurs, organisations, réseaux, thèse de doctorat d'histoire contemporaine, Université de Paris X-Nanterre, 2002, p. 27.

${ }^{17}$ David Bensoussan, Combats pour une Bretagne catholique et rurale. Les droites bretonnes dans l'entre-deux-guerres, Paris, Fayard, 2006, p. 142 et plus largement son chapitre IV, « La condamnation de l'Action française », p. 103-142.

${ }^{18}$ Les Camelots du roi sont les troupes de choc de la ligue. Sur ces derniers, voir Xaxier Cheneseau, Camelots du roi. Les troupes de choc royalistes (1908-1936), Boulogne-Billancourt, Éditions Défi, 1997, 99 p.

${ }^{19}$ Voir sur ce point Michel Leymarie, Albert Thibaudet, "L'outsider du dedans », Villeneuve d'Ascq, Presses Universitaires du Septentrion, 2006, notamment p. 213-224.

${ }^{20}$ Il lui explique le 13 juin 1924 qu'il vient de s'abonner à L'Action française, journal « remarquablement écrit » et qui lui procure une " puissante distraction" (Walter Benjamin, Correspondance, tome I, 1910-1928, édition établie et annotée par Gershom Scholem et Theodore W. Adorno, traduit par Guy Petitdemange, Paris, Aubier-Montaigne, 1979, p. 320). 
${ }^{21}$ Cet éloge funèbre est reproduit dans Les Cabiers Charles Maurras, $\mathrm{n}^{\circ} 8$ (1963), p. 18.

${ }^{22}$ Voir en particulier les débats « autour du parti de l'intelligence » que met bien en lumière Jacques Prévotat, dans Pierre Colin, dir., Intellectuels chrétiens et esprit des années 1920, Paris, Cerf, 1997, p. 169-193.

${ }^{23}$ Pour un panorama rapide, voir Catherine Pomeyrols et Claude Hauser, dir., $L$ 'Action française et l'étranger. Usages, réseaux et représentations de la droite nationaliste française, Paris, L'Harmattan, 2001.

${ }^{24}$ L'ouvrage fondamental est celui d'Eric Defoort, Charles Maurras en de Action française in Belgie, Bruges, Uitgeverij Orion, 1978, 430 p. Ce travail n'a pas été publié en français.

${ }^{25}$ Voir en particulier Alain Clavien, Les Helvétistes. Intellectuels et politique en Suisse romande au début du siècle, Société d'histoire de la Suisse romande \& Éditions d'en bas, Lausanne, 1993, notamment p. 125-126, p. 149-155 et p. 158-159, p. 192-193.

${ }^{26}$ António Costa Pinto, The Blue Shirts, Portugal Fascists and the New State, Social Science Monographs, Boulder, distributed by Columbia University Press, 2000, p. 11.

${ }^{27}$ Voir à ce sujet Pedro González Cuevas, La tradición bloqueada. Tres ideas politicas en España : el primer Ramiro de Maetzu, Charles Maurras y Carl Schmitt, Madrid, Biblioteca Núeva, 2002, p. 77-177 et pour une remise en perspective à l'échelle des droites espagnoles, du même auteur, Elpensamiento politico de la derecha española en el siglo XX. De la crisis de la Restauración al Estado de partidos (1898-2000), Madrid, Tecnos, 2005, p. 48-49, 79, 86-87, 104, p. 111. La réception en Catalogne est étudiée en profondeur et parmi les figures marquées par Maurras sont évoqués notamment le carliste Victor Pradera, le ministre corporatiste Eduardo Aunós ou le publiciste d' $A B C$ Eugenio d'Ors.

${ }^{28}$ C. Stewart Doty, « "Monsieur Maurras est ici” : French Fascism in FrancoAmerican New England ", Journal of Contemporary History, vol. 32, n 4 (octobre 1997), p. 527-538.

${ }^{29}$ Voir en particulier Pierre-Marie Dioudonnat, Je suis partout 1930-1944. Les maurrassiens devant la tentation fasciste, Paris, La Table ronde, 1973, $471 \mathrm{p}$.

${ }^{30}$ Michel Espagne, Les transferts culturels franco-allemands, Paris, PUF, 1999, p. 23.

${ }^{31}$ Cité dans Pierre Trépanier, «Le maurrassisme au Canada français », p. 175. 
${ }^{32}$ Catherine Pomeyrols, «Les intellectuels... », p. 86-87.

${ }^{33}$ Pierre Trépanier s'est attaché à relever minutieusement non seulement les citations de Maurras chez Groulx mais aussi ses emprunts non référencés, notamment à Quand les Français ne s'aimaient pas ("Le maurrassisme... », p. 189-193).

${ }^{34}$ Ibid., p. 183.

${ }^{35}$ Ibid., p. $186-187$.

${ }^{36}$ Charles Maurras, Le dilemme de Marc Sangnier [1906], dans La Démocratie religieuse, Paris, Nouvelle librairie nationale, 1921, p. 34-35.

${ }^{37}$ Michael Sutton, Charles Maurras..., p. 95.

${ }^{38}$ Cité dans Catherine Pomeyrols, "Les intellectuels... », p. 89 (note 4).

${ }^{39}$ Cité dans Catherine Pomeyrols, «Les intellectuels... », p. 88-89. Rappelons qu'en France, la condamnation de l'AF a entraîné la démission de trois ecclésiastiques importants : le cardinal Billot, le père Le Floch, supérieur du séminaire français de Rome et le père Pègues, régent des études au couvent dominicain de Saint-Maximin (Jacques Prévotat, Les catholiques et l'Action franfaise..., p. 478-491).

${ }^{40}$ Études, 120 (1909), p. 620 (cité dans Michael Sutton, Charles Maurras..., p. 128).

${ }^{41}$ Michael Sutton, Charles Maurras..., p. 227.

${ }^{42}$ Sur tous ces points, se reporter à la seconde partie de l'ouvrage précité de Jacques Prévotat et intitulée « La condamnation de 1914. Les étapes », p. 109194.

${ }^{43}$ Jacques Bainville, Journal, 1901-1918, Paris, Plon, 1948, p. 218 (17 novembre 1918). Bainville y revient le 21 mai 1919 en considérant qu' « il y a deux peuples avec qui nous n'avons que des intérêts communs et pas d'intérêts contraires ». Et de citer la Belgique et la Roumanie (Joumal 1919-1926, Paris, Plon, 1949, p. 14).

${ }^{44}$ Eric Defoort, «L'Action française dans le nationalisme belge 1914-1918 », Rerue belge d'bistoire contemporaine, archives VII, (1-2, 1976), p. 148.

${ }^{45}$ Ibid., p. 149.

${ }^{46}$ Jacques Prévotat, Les catholiques et l'Action française..., p. 236 et suiv. 
${ }^{47}$ Cécile Vanderpelen-Diagre, «À l'ombre des clochers. Le monde catholique et la littérature au Québec (1918-1939) ", Revue d'bistoire de l'Amérique frangaise, volume $58, \mathrm{n}^{\circ} 1$ (été 2004), p. 8-9.

${ }^{48}$ Cité dans Susan Mann, Lionel Groulx et l'Action française. Le nationalisme canadien-français dans les années 1920, Montréal, VLB, 2005 [1975], p. 145.

${ }^{49}$ Catherine Pomeyrols, «Les échos de la condamnation de L'Action française au Québec », dans Catherine Pomeyrols et Claude Hauser, dir., L'Action française et l'étranger..., p. 79.

${ }^{50}$ Jean-Claude Dupuis, «La pensée politique de L'Action française de Montréal (1917-1928) ", Cabiers d'bistoire du Québec du XX' siècle, $\mathrm{n}^{\circ} 9$ (été 1994), $\mathrm{p}$. 39. Il relève que L'Action française de Montréal n'a traité qu'une fois d'une œuvre de Maurras, une préface au livre de Marius André, Le déclin de l'empire espagnol. Sur ce Provençal qui fut consul en Espagne pendant dix ans et l'un des principaux hispanophile de L'Action française, voir Pedro González Cuevas, La tradición bloqueada. Tres ideas políticas en España: el primer Ramiro de Maetzu, Charles Maurras y Carl Schmitt, p. 102-107.

${ }^{51}$ L'Action française, "Avis important", janvier 1928, cité in Catherine Pomeyrols, «Les intellectuels nationalistes québécois... », p. 85.

${ }^{52}$ Catherine Pomeyrols, «Les intellectuels nationalistes québécois... », p. 86.

${ }^{53}$ Cité in Catherine Pomeyrols, "Les intellectuels nationalistes québécois... », p. 86.

${ }^{54}$ Ce célèbre passage de l'introduction du Dilemme de Marc Sangnier [décembre 1906] (L'xuvre de Charles Maurras, tome II, La démocratie religieuse, Nouvelle librairie nationale, 1921, p. 26) a été reproduit des décennies plus tard pour ouvrir, en 1963, le huitième numéro des Cabiers Charles Maurras, numéro spécial d'hommage à Charles Maurras pour le dixième anniversaire de sa mort. Les italiques figurent dans le texte original.

${ }^{55}$ Jean Bruchési, Jours éteints, Montréal, Librairie d'action canadienne-française, 1929, p. 198 (cité dans Pierre Trépanier, « Le maurrassisme ... », p. 209).

${ }^{56}$ Denis Chouinard, «Des contestataires pragmatiques : Les Jeune-Canada 1932-1938 ", Revue d'bistoire de l'Amérique française, vol 40, nº 1 (été 1986), p. 9.

${ }^{57}$ Sur cette dernière, voir Nicolas Kessler, Histoire politique de la Jeune Droite (1929-1942). Une Révolution conservatrice à la française, préface de Jean-Louis Loubet del Bayle, Paris, L'Harmattan, 2001. 
${ }^{58}$ Nous nous permettons de renvoyer ici à Olivier Dard, «Existe-t-il une Jeune droite dans l'Europe des années trente ?", dans Olivier Dard, Étienne Deschamps, Les relèves en Europe d'un après-guerre à l'autre. Racines, réseaux et postérités, Bruxelles, PIE Peter Lang, 2005, p. 21-52.

${ }^{59}$ Viure, $2^{\text {ème }}$ cahier, $1^{\text {ère }}$ série (15 juin 1934).

${ }^{60}$ Jean-Louis Gagnon, «Les beautés du régime », L'iure, ${ }^{\text {ème }}$ cahier, $1^{\text {ère }}$ série (15 juin 1934).

${ }^{61}$ Virre, novembre 1934, p. 4.

${ }^{62}$ Vivre, $2^{\text {ème }}$ série, $\mathrm{n}^{\circ} 4$ (26 avril 1935), p. 1.

${ }^{63}$ L'ivre, février 1935, p. 5.

${ }^{64}$ Vivre, février 1935, p. 3.

${ }^{65}$ Jean-Louis Gagnon, «Économique », Vivre, 15 mai 1935, p. 2.

${ }^{66}$ Vivre, novembre 1934, p. 18-19.

${ }^{67}$ Voir en particulier Qu'est-ce que le fascisme? Histoire et interprétation, Paris, Gallimard, 2004, chapitre 3.

${ }^{68}$ André J. Bélanger a fort bien relevé que « sa position en faveur du fascisme italien est patente par le vide de son contenu " (L'apolitisme des idéologies québécoises. Le grand tournant de 1934-1936, Québec, Presses de l'Université Laval, 1974, p. 333).

${ }^{69}$ Philippe Vaillancourt, « Débâcles », Vivre, $2^{\text {ème }}$ cahier, $1^{\text {̀̀re }}$ série (15 juin 1934).

${ }^{70}$ Cette lettre est parue dans le numéro de Vivre d'octobre 1934 ( $\left({ }^{\text {ime }}\right.$ cahier, $1^{\text {ìre }}$ série), p. 24. L'origine de cette lettre semble venir d'une rencontre entre Pierre Chaloult et Dommange sur un bateau, Le Champlain.

${ }^{71}$ On songe en particulier au célèbre chapitre VI de Lucien Rebatet dans Les Décombres, pamphlet paru chez Denoël en 1942: «Au sein de "l'inaction française" » (p. 111-130) auquel l'écrivain opposait un impératif personnel "Que vienne donc enfin le temps de l'action " (p. 14). Rebatet commentait d'ailleurs à sa façon (p. 130) l'influence doctrinale de l'AF hors de France : "Certains de ses plus justes principes ont pu connaitre une grande fortune dans le monde. La belle jambe que cela nous fait! Jusqu'ici, ils sont restés lettre morte pour le gouvernement de la France qui seul nous importait. »

${ }^{72}$ Paul Péladeau, On disait en France, préface d'Édouard Montpetit, Montréal, Éditions Variétés, 1941, p. 213-218. 
${ }^{73}$ Michel Bock, Quand la nation débordait les frontières. Les minorités françaises dans la pensée de Lionel Groulx, Cahiers du Québec, Éditions Hurtubise HMH, 2004, p. 332. Michel Bock (p. 333-337) remet d'ailleurs en perspective les liens entre les rédacteurs de La Nation et l'abbé Groulx : s'il n'a « jamais publiquement répudié » la publication, sa correspondance avec eux le montre « incapable d'adhérer pleinement à leur programme ».

${ }^{74}$ Pierre-Marie Dioudonnat, Je suis partout, 1930-1944. Les maurrassiens devant la tentation fasciste, p. 243-244.

${ }^{75}$ Robert Comeau, «Lionel Groulx, les indépendantistes de la Nation et le séparatisme (1936-1938) ", Revue d'bistoire de l'Amérique française, juin 1972, p. 85. Les Jeunesses patriotes ont publié un journal intitulé L'Indépendance, lequel a cessé de paraitre lorsque le groupe a fusionné avec l'équipe de La Nation (Louise Bienvenue, Quand la jeunesse entre en scène. L'Action catbolique avant la Révolution tranquille, Montréal, Boréal, 2003, p. 38).

${ }^{76}$ André J. Bélanger, L'apolitisme..., p. 336.

${ }^{77}$ Sur les enjeux d'une tentation fasciste au Canada français, voir Robert Comeau, " La tentation fasciste du nationalisme canadien-français avant la guerre, 1936-1939», Bulletin d'bistoire politique, 3, 3/4 (1995), et Robert Arcand, "Les catholiques du Québec et le fascisme italien ", Cabiers d'bistoire, 8 (printemps 1988), p. 5-37.

${ }^{78}$ Michel Lacroix, « Lien social, idéologie et cercles d'appartenance : le réseau "latin" des Québécois en France, 1923-1939", Études littéraires, vol. 36, automne 2004, p. 55-56.

${ }^{79}$ " Jacques Bainville », La Nation, $1^{\text {er }}$ février 1936. L'hommage est appuyé et lyrique : «Comme un grand arbre tout plein de sève qui tombe sous la cognée, Bainville, cet écrivain débordant de promesses, vient de mourir, jeune encore, à l'âge de 57 ans. » La seule réserve exprimée sur ce " présent des dieux au journalisme français » est que «Bainville avait commis la faute impardonnable de ne jamais venir au Canada : sa réputation en souffrira ».

${ }^{80}$ Jean-Marc Dufrenne, "Déclin de l'Action française ", La Nation, 29 février 1936, p. 4 et La Nation, 7 mars 1936, p. 3.

${ }^{81}$ Jean-Marc Dufrenne, « Déclin de l'Action française ", La Nation, 7 mars 1936, p. 3.

${ }^{82}$ Ibid.

${ }^{83}$ Ainsi La Nation, (17 décembre 1936), p. 2 reproduit un article de Frontières, « Une honte pour la France » : «C'est de l'emprisonnement de Charles Maur- 
ras que nous voulons parler. Tous les Français dignes de ce nom ont ressenti l'outrage fait à la pensée française par l'arrestation d'un de ses plus nobles représentants, opérée avec une insigne muflerie, en exécution d'un jugement inique ».

${ }^{84}$ Lionel Groulx a laissé dans ses Mémoires, (tome 3 : 1926-1939, Montréal, Fides, p. 357-358) un portrait grinçant de Berthelot Brunet en évoquant la réception de Directives, recueil d'articles et de discours publié en $1937:$ « Le livre ne passe pas inaperçu. Parmi les éloges, relèverai-je, à côté d'appréciations de jeunes, les plus inattendus ou les plus amusants ? Voici d'abord, dans $\mathrm{La}$ Liberté de Winnipeg, 5 janvier 1938, un article de Berthelot Brunet, l'insigne tapeur qui venait régulièrement me quêter une couple de piastres, sous le prétexte d'un voyage à Lachine qu'il ne faisait jamais, ou pour la publication d'un livre qui n'était pas encore écrit. C'est ce même clochard des lettres qui, pour s'être vu fermer ma porte alors que, grippé, je devais garder la chambre, se retournerait bientôt contre son tapé de chaque quinzaine et lui servirait, dans Les Idées d'Albert Pelletier, un éreintement en règle. Donc, en janvier 1938, ce cher Berthelot écrit entre autres choses : “Au fait, M. Lionel Groulx est écrivain plus nuancé qu'on ne le croit d'ordinaire. Nuancé, ainsi que fort intelligent... M. Lionel Groulx nous donne par sa vie laborieuse, sa vie généreuse, sa vie enthousiaste, sa vie dangereuse... il nous donne l'un des plus purs exemples d'un homme, d'un homme véritable que je sache...Directives nous est un présent d'honneur." En 1934 ce cher Berthelot m'avait écrit de bien autres éloges lors de la publication de mon Jacques Cartier. »

${ }^{85}$ "La cellule de Maurras », La Nation, 21 janvier 1937, p. 2 . On trouve chez Berthelot Brunet (1901-1948) dans son Histoire de la littérature canadiennefranf̧aise publiée aux Éditions de l'Arbre à Montréal en 1946, diverses références à l'Action française de Paris à laquelle il rend hommage. Ainsi, il rattache l'écho de L'Action française de Paris à celui du Devoir: "Toutes révérences gardées, et bien qu'il ne comptât jamais de Maurras, de Daudet et bien que les Bainvilles [sic] lui fissent singulièrement défaut, le Devoir exerça une influence analogue à celle de L'Action française de Paris. Comme le quotidien de la rue de Rome, il avait même ses succursales, dans l'espèce des revues et d'autres périodiques » (p. 97). Par la suite, lorsqu'il évoque Robert Rumilly (p. 117), il commence par mentionner ses origines françaises et souligne que « ses réflexions ne cachent pas non plus que l'Action française exerça une vive influence ; mais en cela Rumilly serait assez canadien. »

${ }^{86}$ Le numéro du 8 juillet 1937 est accompagné en manchette d'une citatión de Maurras tirée de L'Étang de Berre et en première page d'un article de Paul Bouchard intitulé «Charles Maurras sort de prison » où le directeur de $\mathrm{La}$ 
Nation voit en Maurras « le plus grand penseur politique de la France moderne et l'un de ses plus grands écrivains » et rend hommage à son « influence universelle »: « N'est-il pas le penseur dont la doctrine a donné naissance à tant de mouvements de droite qui se sont dressés en face du bolchevisme asiatique ? N'est-il pas le défenseur attitré et militant en face du flot montant de la barbarie des normes éternelles de la civilisation gréco-latine ? Mussolini et Salazar, deux remparts du monde latin, rénovateurs de leurs patries et créateurs d'un nouveau type de civilisation, ne sont-ils pas deux disciples de Maurras ? Et l'Espagne de Franco elle-même ne se revendique-t-elle pas de lui comme l'attestait, il n'y a pas encore très longtemps, la revue Frontières? Un fait historique indiscutable, c'est que Charles Maurras a exercé une influence universelle qui le porte au rang des plus grands esprits qu'ait produits la France. » Nous n'épiloguerons pas sur l'influence supposée de Maurras sur les dictateurs précités. Si on laisse de côté le cas de Salazar, dont certains maurrassiens français d'Henri Massis à Michel Déon ont laissé des portraits élogieux et souligné la proximité avec le penseur martégal, il faut signaler, concernant Franco, que le nom de Maurras n'apparait même pas à l'index de ses principaux biographes (Paul Preston, Francisco Franco, Milano, Montadori, 1995, André Bachoud, Franco ou la réussite d'un homme ordinaire, Paris, Fayard, 1997 etc.). Par ailleurs, les travaux sur les origines et les cheminements de la pensée de Mussolini ne font pas de place à l'influence du théoricien monarchiste (Didier Musiedlak, Mussolini, Presses de Sciences Po, 2005 - voir en particulier le chapitre IV, « Le primat de la culture »). Didier Musiedlak nous a par ailleurs indiqué que Maurras est seulement cité trois fois dans les 36 volumes des Opera Omnia, a cura di Eduardo e Diulio Susmel, Florence, La Fenice 1956, tome XVII [1922], p. 396 (à propos de la conférence de Cannes), tome XXVI [1933] p. 38 (à l'occasion d'un commentaire de Léon Daudet où Mussolini se félicite du tableau favorable qu'il dresse du fascisme italien, mais en profite pour en souligner les singularités et l'originalité) et enfin tome XXVIII [1937], p. 215 (Maurras est cité parmi les grands polémistes français, avec Rochefort et Clemenceau).

${ }^{87}$ Marcel Hamel, «Les deux Maurras », La Nation, 29 juillet 1937, p. 3.

${ }^{88}$ Il faut souligner qu'Henri d'Orléans et le Courrier royal ne sont même pas mentionnés. Quelques mois plus tard, le 3 mars 1938, dans un texte intitulé "Le drame intérieur de Charles Maurras », Hamel évoque "L'évènement le plus pathétique jamais produit dans la politique européenne, c'est bien le reniement de l'Action française et de ses chefs par les princes. Il y a là quelque chose de lugubrement ingrat dans ce geste de réprobation ».

${ }^{89}$ Marcel Hamel, «Charles Maurras en nous », La Nation, 10 juin 1937, p. 2. 
${ }^{90}$ Ibid., p. 2.

${ }^{91}$ Marcel Hamel, « Maurras et Barrès », La Nation, 2 septembre 1937, p. 3.

${ }^{92}$ Ibid., p. 3.

${ }^{93}$ Marcel Hamel, «Sur le dernier ouvrage de Jean-Charles Harvey: Art et combat ", La Nation, 3 février 1938, p. 2.

${ }^{94}$ Marcel Hamel, «Charles Maurras en nous », La Nation, 10 juin 1937, p. 2.

${ }^{95}$ Julien Fabre, «La Nation : les groulxiens devant la tentation fasciste 19361939 », Bulletin d'histoire politique, vol. 9, $\mathrm{n}^{\circ} 2$ (printemps 2001), p. $42-43$ (dossier thématique «Le Québec des années trente : une société à la recherche de son avenir »). Sur les relations de Lionel Groulx et La Nation, voir Robert Comeau, «Lionel Groulx, les indépendantistes de La Nation et le séparatisme (1936-1938) », qui s'interroge sur les relations entre Groulx et ses « disciples audacieux » p. 92-94 et Michel Bock, Quand la nation..., p. 332-337.

${ }^{96}$ Marcel Hamel, «Les deux Maurras », 29 juillet 1937, p. 3

${ }^{97}$ Cette position n'est pas celle des maurrassiens de la Jeune Droite conduits par Thierry Maulnier dont la tentation fasciste repérée dans les périodiques Combat et L'Insurgé en 1936-1937 n'est ni durable ni facteur de rupture avec le monarchisme d'AF. Sur cette question, voir Nicolas Kessler, Histoire politique de la Jeune Droite (1929-1942). Une révolution conservatrice à la franşaise, Paris, L'Harmattan, 2001, p. 388-400 et les analyses de Ludovic Morel, Tbierry Maulnier et l'Action francaise, master d'histoire contemporaine, Université de Franche-Comté, 2005, notamment le chapitre VII « Maulnier et la Jeune Droite vont-ils s'insurger contre Maurras ? ", p. 183-231.

${ }^{98}$ "Je suispartout et M. Dostaler O'Leary », La Nation, 10 février 1938, p. 3. Ces compliments tressés, Roger Vézina regrette que le programme séparatiste ne soit pas présenté avec assez de pédagogie pour un public français.

${ }^{99}$ Cette lettre, unique en son genre, est conservée au CARAN, 576 AP carton 62, chemise Canada. Si ne figure que la seule mention « juin 1937 », elle a été postée le 9 juin et adressée à la prison de la Santé où Maurras est alors détenu. ${ }^{100}$ Souligné par nous. On mesure ici la différence profonde entre la pensée de Marcel Hamel et celle de Groulx.

${ }^{101}$ La lettre est conservée au CARAN, 576 AP carton 62, chemise Canada.

${ }^{102}$ Par comparaison, on ne trouve que deux articles de L'Action française reproduits en 1938-1939 : le 24 février, une reproduction d'un article 
de Georges Claude sur l'Espagne et le $1^{\text {er }}$ juin 1939 un texte non signé intitulé "Controverse sur le rexisme ".

${ }^{103}$ Marcel Hamel, «De Charles Maurras à Jacques Maritain », La Nation, 25 août 1938, p. 2. L'article porte sur la question juive et Hamel conclut son propos en empruntant aux deux auteurs dont les positions sont par ailleurs bien différentes.

${ }^{104}$ La Nation, 23 juin 1939, p. 2.

${ }^{105}$ Sur cette création et son échec, Bertrand Joly, Dictionnaire biograpbique et géographique du nationalisme français (1880-1900), Paris, Honoré Champion, 1998, p. 669-670.

${ }^{106}$ Julien Thévet, "Un grand Canadien : le chanoine Groulx », Aspects de la France, 22 mai 1975, p. 8.

${ }^{107}$ Cité dans Catherine Pomeyrols, «Les intellectuels nationalistes québécois... ", p. 86.

${ }^{108}$ De son côté, Susan Mann, Lionel Groulx..., p. 35, a retenu 600 citations ou allusions à l'Action française parisienne dans les publications nationalistes québécoises contre 20 concernant le Canada dans le quotidien français.

${ }^{109} \mathrm{Il}$ s'agit d'un journal franco-américain de Worcester (Massachussets). Voir sur ce point Yves Roby, Les Franco-Américains de la Nouvelle-Angleterre. Rêves et réalités, Sillery, Septentrion, 2000.

${ }^{110}$ Lettre de Robert Rumilly à Maurras, 14 juillet 1937, CARAN, 576 AP carton 62, chemise Canada.

${ }^{111}$ Dictionnaire politique et critique. Complément établi par les soins de Jean Pélissier, non daté, fascicule n ${ }^{\circ}$, Paris Cahiers Charles Maurras, p. 217, L'Action française, (27 juillet 1936).

${ }^{112}$ Ibid., p. 216-217, L'Action française, 30 août 1934.

${ }^{113}$ Ibid., p. 219, L'Action française, 29 mars 1937.

${ }^{114}$ Ibid., p. 220-221, L'Action française, 29 mars 1937.

${ }^{115}$ Ibid., p. 217, L'Action française, 30 août 1934.

${ }^{116}$ Sur ce dernier, voir Mason Wade, Les Canadiens français de 1760 à nos jours, tome II, cercle du livre de France, 1963, p. 305-306 et Michel Bock, Quand la nation..., p. 306. 
${ }^{117}$ Si, dans le texte de Maurras, aucun nom n'est cité, il faut souligner qu'il a reçu un courrier de Louis D. Durand qui a adressé le 12 mars 1937 à son « Très vénéré Maître » un article d'Omer Héroux (du Devoir) et diverses coupures de presse en référence au Deuxième Congrès de la langue française venant du Canada et même de Louisiane (CARAN, 576 AP carton 62, chemise Canada).

${ }^{118}$ Dictionnaire politique et critique. Complément établi par les soins de Jean Pélissier, non daté, fascicule $\mathrm{n}^{\circ} 3$, Paris Cahiers Charles Maurras, p. 219, L'Action française, 29 mars 1937.

${ }^{119}$ Charles Maurras, Dictionnaire politique et critique, 1932.

${ }^{120}$ Sur tous ces points, voir Michel Bock, op. cit., p. 178 et suiv.

${ }^{121}$ Dans son article «La croisée des chemins ", L'Action francaise, mars 1922, p. 148, Louis D. Durand imaginait un État composé du Québec, des trois provinces maritimes, d'une partie de l'Ontario et sans doute des régions frontalières où vivaient des Canadiens français (Michel Bock, op. cit., p. 306).

${ }^{122}$ Courrier précité du 12 mars 1937, (CARAN, 576 AP carton 62, chemise Canada).

${ }^{123}$ Cette revue a absorbé en février 1933 La Revue d'Amérique latine publiée mensuellement à partir de janvier 1922 et où Charles Maurras avait proposé sa définition de la latinité, ce qui ne fait cependant pas de cette revue un organe maurrassien, même si son directeur, Charles Lesca, est d'AF. Si la RAL a publié 27 articles et comptes rendus de et sur des écrivains canadiens, le Canada n'a plus « aucune place » dans Frontières (Michel Lacroix, « Lien social, idéologie... », p. 53-54).

${ }^{124}$ Voir «L'internationale des Rois : oui ; I'Internationale blanche non ", Charles Maurras, Dictionnaire politique et critique, établi par les soins de Pierre Chardon, tome deuxième, Paris, À la cité des livres, 1932, p. 325-326.

${ }^{125}$ Cité dans Pierre Trépanier, « Le maurrassisme... », p. 210.

${ }^{126}$ Cité dans Paul Péladeau, On disait en France, p. 212.

${ }^{127}$ Signé AC, il est paru en octobre 1941 (p. 165).

${ }^{128}$ Le Devoir, 22 mars 1941, cité dans Pierre Trépanier, « Le maurrassisme... », p. 211.

${ }^{129}$ Il ne faudrait pas négliger l'importance de la guerre d'Espagne dont Catherine Pomeyrols montre, à partir du dépouillement exhaustif du Devoir « $\mathrm{Le}$ Devoir et la guerre d'Espagne. Les usages de la référence française », Revue d'bistoire de l'Amérique française, hiver 2005, p. 351-356) que la presse 
maurassienne est citée (Action française, Revue universelle, sans oublier Je suis partout où les maurrassiens sont nombreux).

${ }^{130}$ Pierre Trépanier, "Le maurrassisme... », p. 216 cite une série d'articles parus dans le Quartier latin en février-mars 1945 à l'occasion du procès de Charles Maurras sous la plume de Jean-Baptiste Boulanger et qui sont un hommage au penseur martégal.

${ }^{131}$ Cabiers Charles Maurras, $\mathrm{n}^{\circ} 8,1963$.

${ }^{1.32}$ Cette vision est partagée par L'Action française de Montréal. Voir sur ce point l'article d'Antonio Perrault, "Sur une préface de Charles Maurras ", L'Action francaise, vol 7, $\mathrm{n}^{\circ} 4$, (avril 1922), p. 243. Soulignons que cette vision imprègne aussi la revue de Jacques Reynaud, Latinité : revue despays d'Occident, parue entre 1929 et 1932. Son second numéro (1930) a d'ailleurs consacré sous la plume de J-M. Carrière un dossier aux lettres canadiennes (p. 245-252) qui évoque le congrès de 1912 et la naissance de la Ligue d'Action française en 1913.

${ }^{133}$ Michael Sutton, Charles Maurras..., p. 61-63. 